\title{
The strut-and-tie model and the finite element - good design companions
}

\author{
Ahmed K. Ghoraba1 ${ }^{1 D}$, Salah E. El-Metwally *2 iD, Mohamed E. El-Zoughiby ${ }^{2}$ iD \\ ${ }^{1}$ Misr Higher Institute of Engineering and Technology, El-Mansoura, Egypt \\ ${ }^{2}$ Mansoura University, Structural Engineering Department, El-Mansoura, Egypt
}

\begin{abstract}
The strut-and-tie method (STM) can serve as a tool for a safe design of concrete structures or members. It aids to trace the flow of forces, appropriately lay-out the reinforcement, and safely predict the structure capacity. On the other hand, the linear elastic finite element can be utilized as an alternative in the development of the strut-and-tie models besides the load path method. In addition, the nonlinear finite element analysis assists in the optimization of the design results obtained from the STM. Hence, the two methods work well as companions in structural design. In order to demonstrate such understanding, different examples which include a deep beam with large opening and recess, continuous deep beams with and without openings, and beam ledges, have been utilized. In the STM solutions, the ACI 318-14 failure criteria have been adopted. In the nonlinear finite element analysis, material nonlinearity has been accounted for. The obtained solutions from the two methods, along with the experimental data of the selected examples of this study, revealed the reliability of the STM in obtaining a safe solution. Besides, the nonlinear finite element proved to be an efficient tool in obtaining an economic design.
\end{abstract}

\section{Keywords}

Reinforced concrete design; Discontinuity regions; Strut-and-tie model; Nonlinear finite element analysis; Deep beams; Beam ledge

Received: 22 June 2020; Accepted: 03 November 2020

ISSN: 2630-5763 (online) C 2020 Golden Light Publishing All rights reserved.

\section{Introduction}

The method of the strut-and-tie model, STM, has been well established in both academia and practice for the treatment of discontinuity (D) regions; e.g., deep beams, openings, corbels, etc. [1,2]. The STM, is a logical extension of the truss model by Ritter [3] and Mörsch [4], and the major difference between the two methods is that the strut-and-tie model is a set of forces in equilibrium but do not form a stable truss system. Thus, the STM is a generalization of the truss model by Schlaich et al.
[2] and Schlaich and Schäfer [5]. The method has been adopted by many codes of practice such as the ACI 318-14 Code [6], the Eurocode 2 [7], the Canadian Standards Association [8], and the CEBFIP Guidelines [9,10].

On the other hand, the implementation of the nonlinear finite element analysis, NFEA, in practice is very limited. Due to its very intensive computation efforts, the method can only serve as a benchmark for other methods or solutions. This makes the method of STM appealing in practice for both strength assessment and design.

\footnotetext{
* Corresponding author

Email: selmetwally@mans.edu.eg
} 
In order to achieve a good design, the STM can serve as a reliable design tool that aids to trace the flow of forces and achieve successful detailing. For the development of the STM, the load path method can be used in most of the cases; however, in some cases, it becomes easier and a straightforward matter if a linear elastic finite element analysis is employed. Since the STM is a lower-bound solution, the design obtained from this method is always on the safe side. For a given design, if optimization is required, the NFEA can serve this purpose. Thus, both the STM and the finite element work together as good design companions. This understanding is demonstrated in this paper by many examples. These examples include deep beams with large openings and recess, continuous deep beams with and without large openings, and beams with ledges.

In the STM solutions presented herein, the failure criteria of the ACI 318-14 Code [6], are adopted. As for the linear/nonlinear finite element analyses, the computer software ABAQUS [11] is utilized. In the NFEA, material nonlinearity is accounted for. Most of the examples discussed in this paper had been tested experimentally. Comparisons between the experimental data and the predicted results by the STM and the NFEA are performed. The comparisons revealed the reliability of the STM in obtaining a safe solution. Also, the NFEA proved to be an efficient tool in obtaining an economic design.

\section{The strut-and-tie method}

An STM consists of three types of elements; concrete struts (with or without reinforcement), ties with or without reinforcement, nodes, and nodal zones, Fig. 1. Any STM may fail by one of the following modes: yield or anchorage failure of the tension tie, one of the struts could crush when the stress in the strut exceeds the effective compressive strength of concrete, or a nodal zone could fail by being stressed beyond its capacity. In this paper, the failure criteria of the ACI 318-14 Code [6] are employed in the presented applications.

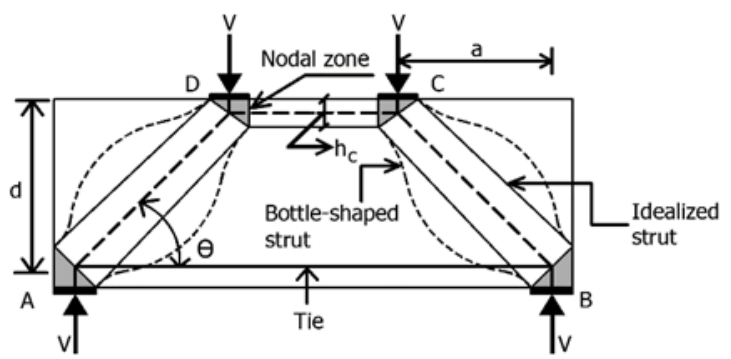

Fig. 1. Components of a strut-and-tie model of a deep beam

\subsection{Strength of struts}

According to the ACI 318-14 [6] the nominal compressive strength of a strut without longitudinal reinforcement, $F_{n s}$, shall be taken as

$F_{n s}=f_{c e}^{s} A_{c s}$

where $f_{c e}^{s}$ is the smaller of:

- The effective compressive strength of the concrete in the strut.

- The effective compressive strength of the concrete in the nodal zone.

and $A_{c s}$ is the cross-sectional area at one end of the strut. In calculating $A_{c s}$, the strut width is measured perpendicular to the strut axis at its end.

The effective compressive strength of the concrete in a strut $f_{c e}^{S}$ can be obtained from

$f_{c e}^{s}=0.85 f_{c}^{\prime} \beta_{s}$

where $f_{c}^{\prime}$ is the concrete cylinder strength and $\beta_{s}$ is an effectiveness factor of concrete. Table 1 shows the values of $\beta_{s}$ according to the ACI 318-14 Code [6], in which the influence of the stress conditions, strut geometry, and the angle of cracking surrounding the strut on strength are reflected.

\subsection{Nodal zones}

Smeared nodes do not need to be checked if the reinforcement is properly developed until the extremities of the stress field. A check of concrete stresses in the singular nodes is necessary because of the stress concentration at these nodal regions. The singular nodes are divided into four major types, C-C-C, C-C-T, C-T-T, and T-T-T nodes, where $\mathrm{C}$ and $\mathrm{T}$ stand for compression and tension, respectively. 
Table 1. ACI 318-14 code values of coefficient $\beta_{s}$ for struts [6]

\begin{tabular}{ll}
\hline \multicolumn{1}{c}{ Strut condition } & $\beta_{S}$ \\
\hline - A strut with constant cross-section along its length & 1.0 \\
- & For struts located such that the width of the midsection of the strut is larger than the width at the nodes \\
(bottle-shaped struts) & 0.75 \\
a) With reinforcement normal to strut center-line to resist the transverse tension & $0.6 \lambda$ \\
b) Without reinforcement normal to the center-line of the strut & 0.40 \\
- For struts in tension members, or the tension flanges of members & $0.6 \lambda$ \\
\hline
\end{tabular}

The effective compressive strength of the concrete in a nodal zone, $f_{c e}^{n}$, can be obtained from:

$f_{c e}^{n}=0.85 f_{c}^{\prime} \beta_{n}$

where $\beta_{n}$ is the effectiveness factor of a nodal zone. Table 2 shows the effectiveness factor, $\beta_{n}$, for nodal zones according to the ACI 318-14 Code [6].

\subsection{Reinforced ties}

The nominal strength of a tie, $F_{n t}$, shall be taken as $F_{n t}=A_{s t} f_{y}$; where $A_{s t}$ is the area of steel and $f_{y}$ is the yield stress. The width of a tie $w_{t}$, is to be determined to guarantee node safety, with an upper limit $w_{t, \max }$.

- In case of using one row of bars without sufficient development length beyond the nodal zones, Fig. 2a:

$w_{t}=0.0$

- In case of using one row of bars and providing sufficient development length beyond the nodal zones for a distance not less than $2 c$, where $c$ is the concrete cover, Fig. $2 b$ :

$w_{t}=\emptyset_{b a r}+2 c$

where $\phi_{\text {bars }}$ is the diameter of the reinforcing bars.

- In case of using more than one row of bars and providing sufficient development length beyond the nodal zones for a distance not less than $s / 2$, where $s$ is the clear distance between bars, Fig. 2c:

$w_{t}=n \emptyset_{\text {bar }}+2 c+(n-1) s$

where $n$ is the number of rows of reinforcing bars. In the three cases in Fig. 2, the development length according to the ACI 318-14 [6], $l_{\text {anc }}$, begins at the intersection of the centroid of the bars in the tie and the extensions of the outlines of either the strut or the bearing area.

For the extended nodal zone, Figs. $2 b$ and $2 c$, the upper limit of the strut width,

$$
w_{t, \max }=\frac{F_{n t}}{b f_{c e}^{n}}
$$

\section{Linear/Nonlinear finite element analysis}

In this study, 3D linear and nonlinear finite element analyses have been performed using the computer software ABAQUS [11]. The constitutive models adopted in the modeling process are briefly described here. The displacement control approach has been employed to accurately predict the capacity and post-cracking behavior of the studied examples.

\subsection{Finite elements of concrete and steel reinforcement}

Herein, the 3D solid continuum element C3D8R has been employed to model concrete. This element is an 8-noded linear brick having 3 translational degrees of freedom at each corner node. The reinforcing steel has been defined as individual truss elements with steel material properties and cross-sections using T3D2 element which is a (2node linear displacement) 3D truss element.

\subsection{Concrete material modeling}

The "Concrete damage plasticity model" (CDP) is utilized for concrete modeling which assumes that the main two failure modes are tensile cracking and compressive crushing [11]. 
Table 2. ACI 318-14 Code values of coefficient $\beta_{n}$ for nodes

\begin{tabular}{lc}
\hline \multicolumn{1}{c}{ Nodal zone } & $\beta_{n}$ \\
\hline For nodal zones bounded by struts or bearing areas or both, C-C-C node & 1.00 \\
Nodal zones anchoring one tie, C-C-T node & 0.80 \\
Nodal zones anchoring two or more ties with the presence of one strut, C-T-T node & 0.60 \\
Nodal zones anchoring ties only, T-T-T node & 0.40 \\
\hline
\end{tabular}

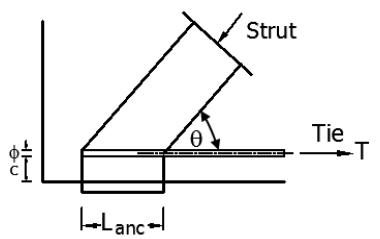

(a) $\mathrm{w}_{\mathrm{t}}=0.0$

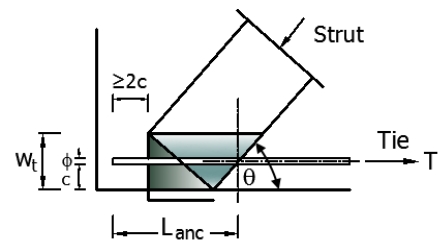

(b) $\mathrm{w}_{\mathrm{t}}=\phi_{\mathrm{bars}}+2 \mathrm{c}$

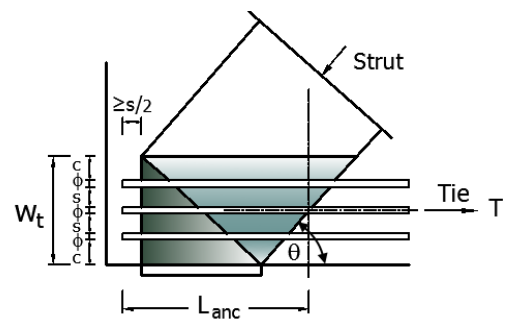

(c) $\mathrm{w}_{\mathrm{t}}=\mathrm{n} \phi_{\text {bars }}+2 \mathrm{c}+(\mathrm{n}-1) \mathrm{s}$

Fig. 2. The width of the tie, $w_{t}$, used to determine the dimensions of the nodal zone

In this paper, the uniaxial compressive stress-strain relationship of the concrete model, as shown in Fig. $3 \mathrm{a}$ is proposed by Saenz [12] as follows:

$\sigma_{c}$

$=\frac{E_{c} \varepsilon_{c}}{1+\left(R+R_{E}-2\right)\left(\frac{\varepsilon_{c}}{\varepsilon_{0}}\right)-(2 R-1)\left(\frac{\varepsilon_{c}}{\varepsilon_{0}}\right)^{2}+R\left(\frac{\varepsilon_{c}}{\varepsilon_{0}}\right)^{3}}$

where $\sigma_{c}$ is the compression stress at any $\varepsilon_{c}$, and $\varepsilon_{0}$ the strain at the ultimate stress.

$R=\frac{R_{E}\left(R_{\sigma}-1\right)}{\left(R_{\varepsilon}-1\right)^{2}}-\frac{1}{R_{\varepsilon}}$

$R_{E} \frac{\varepsilon_{c}}{\varepsilon_{0}}$

$E_{0}=\frac{f_{c}^{\prime}}{\varepsilon_{0}}$

where $R$ is the ratio relation; $R_{E}$ is the modular ratio; $R_{\varepsilon}=4=$ the strain ratio; $R_{\sigma}=4=$ the stress ratio as reported in [13]; $E_{0}$ is the secant modulus. Poisson's ratio for concrete is assumed to be 0.20 .

The softening curve of concrete under tension is shown in Fig. $3 \mathrm{~b}$, where $f_{c t}$ is the tensile strength, and $G_{f}$ is the fracture energy of concrete which is used to specify the post-peak tension failure behavior of concrete. According to the ACI-318 [14], $E_{c}$ and $f_{c t}$ were calculated by:

$$
\begin{aligned}
& E_{c}=4700 \sqrt{f_{c}^{\prime}} \\
& f_{c t}=0.35 \sqrt{f_{c}^{\prime}}
\end{aligned}
$$

\subsection{Reinforcing steel modeling}

The steel reinforcement has been modeled as an elastic-perfectly plastic material in both tension and compression.

\subsection{Bond between steel and concrete}

A perfect bond between concrete and reinforcement has been assumed in this study, which was achieved by using a constrain called Embedded Element. The reinforcing bar is embedded into the concrete host element; thus, all embedded element nodes have the same translational degrees of freedom as the concrete host element's nodes [6].

\section{Deep beam with large opening and recess}

\subsection{Description}

The deep beam in Fig. 4a with an abrupt change of thickness and a large opening was designed to carry a factored concentrated load of $2000.0 \mathrm{kN}$ (or a nominal load $2667.0 \mathrm{kN}$ ) [15]. From the beam geometry, it is entirely considered as a D-region. 


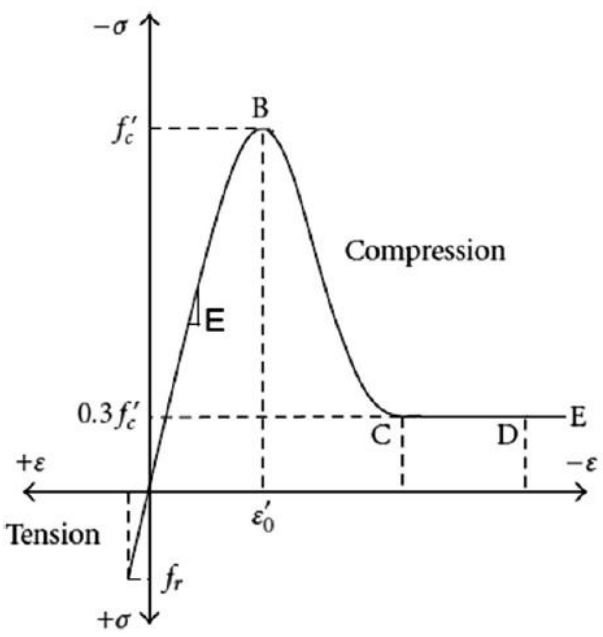

(a) uniaxial compressive stress-strain curve

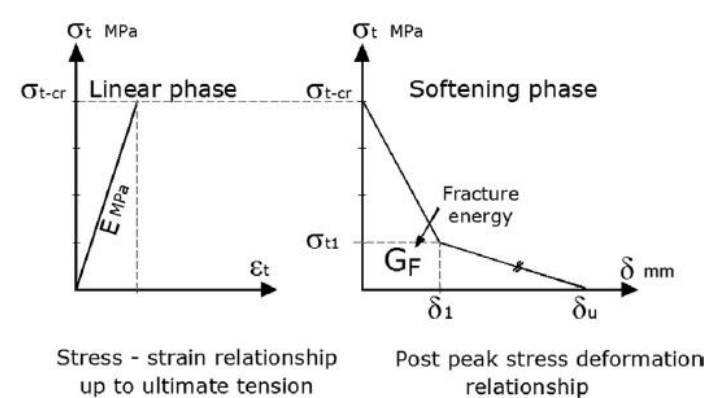

(b) tension stiffening model

Fig. 3. Concrete modeling

This beam is selected for comparison between the two-dimensional strut-and-tie modeling and the 3D nonlinear finite element analysis. Fig. 4 shows the beam geometry, loading, and reinforcement details of the beam.

The cylinder compressive strength of concrete, $f_{c}^{\prime}=31 \mathrm{MPa}$ and the reinforcement is high strength deformed steel bars, with yield stress, $f_{\mathrm{y}}=414$ $\mathrm{MPa}$. The beam height is as shown in Fig. 4a, breadth, $\mathrm{b}=305 \mathrm{~mm}$, the width of the bearing plate $b_{1}=600 \mathrm{~mm}$, and $b_{2}=b_{3}=400 \mathrm{~mm}$.

\subsection{Strut-and-tie modeling}

\subsubsection{Geometrical parameters}

The solution procedure starts with the development of the strut-and-tie model. With the aid of the stress pattern obtained from the linear elastic analysis, it is obvious how the struts go around the opening to transfer their forces to the supports. The proposed STM is shown in Fig. 5a, and for the next illustrations, the details of selected nodes are given in Fig. 5b.

Concerning Figs. 5 and $4 \mathrm{~b}$, the reinforcement 4T32 of tie $T_{1}$ is assumed to be well anchored at nodes 3 and 4 . Hence, the width of this tie (height of nodes 3 and 4$)$ is given by

$w_{T_{1}}=2\left(c+\emptyset_{\text {stirrup }}\right)+n \emptyset_{\text {bar }}+(n-1) s=$ $202 \mathrm{~mm}$.
If tie $T_{1}$ yields, its nominal strength will be $T_{1 n}=A_{s} \times f_{\mathrm{y}}=(4 \times 804.25) \times 414=1332 \mathrm{kN}$.

In the same manner, for the 4T25 reinforcement of each of the ties $T_{2}$ and $T_{3}$, the height of each tie at nodes 6 and 7 is $181 \mathrm{~mm}$ and the nominal strength is $813.0 \mathrm{kN}$.

Regarding Figs. 5 and 4b, the reinforcement of each of the ties $T_{4}$ and $T_{5}$ is 5T13 (2-legs) vertical stirrups T13, spaced at $450 \mathrm{~mm}$ center to center. The width of each of these ties is

$w_{T_{4}}=w_{T_{5}}=n\left(\varnothing_{b a r}+s\right)=2315 \mathrm{~mm}$.

Each of the ties $T_{4}$ and $T_{5}$ has a nominal strength

$T_{4 n}=T_{5 n}=A_{s} \times f_{\mathrm{y}}=(2 \times 5 \times 132.7) \times 414=549.5$ $\mathrm{kN}$.

Also, $T_{6}$ is represented by 9T13 (2-legs) vertical stirrups, spaced at $230 \mathrm{~mm}$ center to center. The nominal strength of the tie $T_{6}$ is

$T_{6 n}=A_{s} \times f_{\mathrm{y}}=(2 \times 9 \times 132.7) \times 414=989.12 \mathrm{kN}$.

The width of this tie is

$w_{T_{6}}=n\left(\emptyset_{\text {bar }}+s\right)=2187 \mathrm{~mm}$

In the same manner, each of the ties $T_{7}, T_{8}, T_{9}$, and $T_{10}$ are represented by $6 \mathrm{~T} 32$, the width of these ties or the height of nodes $10,11,12,13$, and 14 , is $266 \mathrm{~mm}$ and the nominal strength is $1997.75 \mathrm{kN}$. 


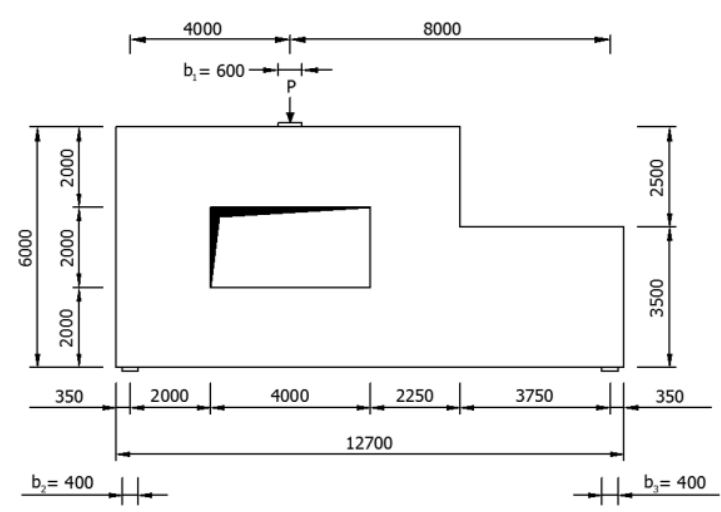

(a) beam geometry (dimensions in $\mathrm{mm}$ ) and loading

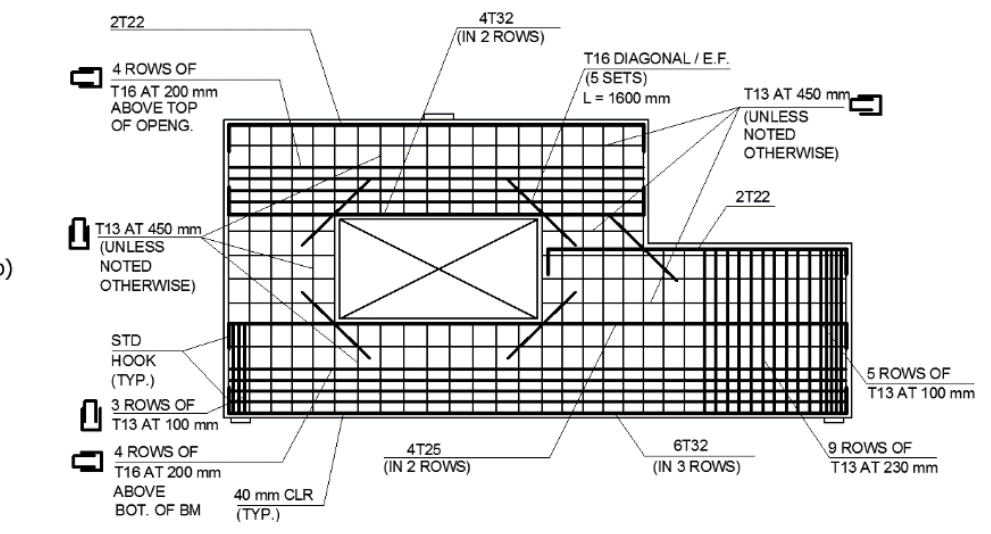

(b) reinforcement arrangement

Fig. 4. Deep beam with large opening and recess

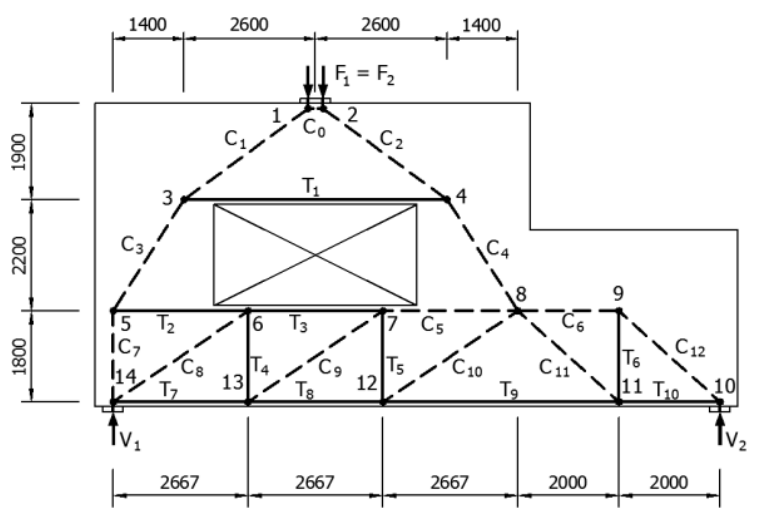

(a) model

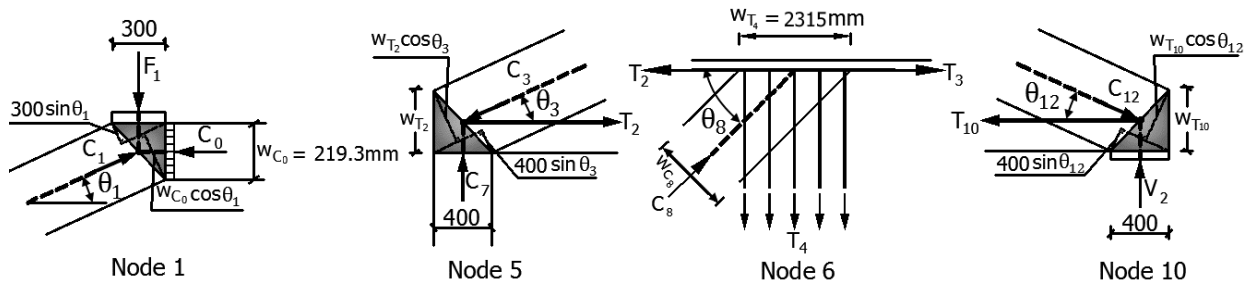

(b) details of selected nodes

Fig. 5. Proposed STM of the deep beam with large opening and recess 


\subsubsection{Reactions}

From equilibrium, $V_{1}=0.67 P$ and $V_{2}=0.33 P$.

\subsubsection{Model geometry and forces}

To obtain the forces in the model elements, the reinforcement of a selected tie was assumed to reach its yield stress. The solution to this problem was initiated by assuming that the reinforcement of tie $T_{2}$ reached its yield stress, $T_{2}=813.0 \mathrm{kN}$. Then, from simple truss analysis, the model forces were obtained, Fig. 6. This led to an applied load $P=$ $F_{1}+F_{2}=2560 \mathrm{kN}$. It is noted that this load value is less than the required nominal strength.

\subsubsection{Effective concrete strength of the struts}

The effective concrete strength of the strut

$f_{c e}^{s}=0.85 f_{c}^{\prime} \beta_{s}$.

For prismatic strut

$f_{c e}^{s}=0.85 \times 31 \times 1.0=26.35 \mathrm{MPa}$.

For bottle-shaped strut with sufficient reinforcement to resist the transverse tension

$f_{c e}^{s}=0.85 \times 31 \times 0.75=19.76 \mathrm{MPa}$

This value will be used throughout the example, and in the end, it will be verified.

\subsubsection{Effective concrete strength of the nodes}

The effective concrete strength of the different nodes, $f_{c e}^{n}=0.85 f_{c}^{\prime} \beta_{n}$, are
For $\mathrm{C}-\mathrm{C}-\mathrm{C}$ node, $f_{c e}^{n}=0.85 \times 31 \times 1.0=26.35 \mathrm{MPa}$

For $\mathrm{C}-\mathrm{C}-\mathrm{T}$ node, $f_{c e}^{n}=0.85 \times 31 \times 0.80=21.08 \mathrm{MPa}$

For C-T-T node, $f_{c e}^{n}=0.85 \times 31 \times 0.60=15.81 \mathrm{MPa}$

\subsubsection{Check the bearing of the nodes}

For nodes 1 and 2, the nominal value of the load $\mathrm{P}$, $P_{n}=26.35 \times 600 \times 305=4822.03 \mathrm{kN}$, which is greater than the applied load, $P=2560 \mathrm{kN}$.

For node 10 , the nominal value of the reaction $V_{2}$, $V_{2 n}=21.08 \times 400 \times 305=2571.75 \mathrm{kN}$, which is greater than the reaction, $V_{2}=853.3 \mathrm{kN}$.

For node 14 , the nominal value of the reaction $V_{1}$, $V_{1 n}=21.08 \times 400 \times 305=2571.75 \mathrm{kN}$, which is greater than the reaction, $V_{1}=1706.7 \mathrm{kN}$.

\subsubsection{Check of stresses}

\section{Node 1:}

Since the bearing stress has been checked before, there is no need to check it again. The width of the tie $T_{10}, w_{T_{10}}=266 \mathrm{~mm}$. Assuming that the force in the prismatic strut $C_{0}$ is equal to its nominal strength; then, $C_{0}=1762.7 \mathrm{kN}=26.35 \times w_{C_{0}} \times 305$, which gives, $w_{C_{0}}=219.3 \mathrm{~mm}$. For strut $C_{1}$, its angle of inclination $\theta_{1}=36.0^{\circ}$, which gives a width of the strut, $w_{C_{1}}^{1}=300 \sin \theta_{1}+219.3 \cos \theta_{1}=353.75 \mathrm{~mm}$. Then, the nominal strength of the strut $C_{1 n}=19.76 \#$ $\times 353.75 \times 305=2132 \mathrm{kN}$ (\# the smaller of the node strength and the strut strength), which is less than the strut force, $C_{1}=2166.7 \mathrm{kN}$; i.e., $C_{1 n}=0.984 C_{1}$.

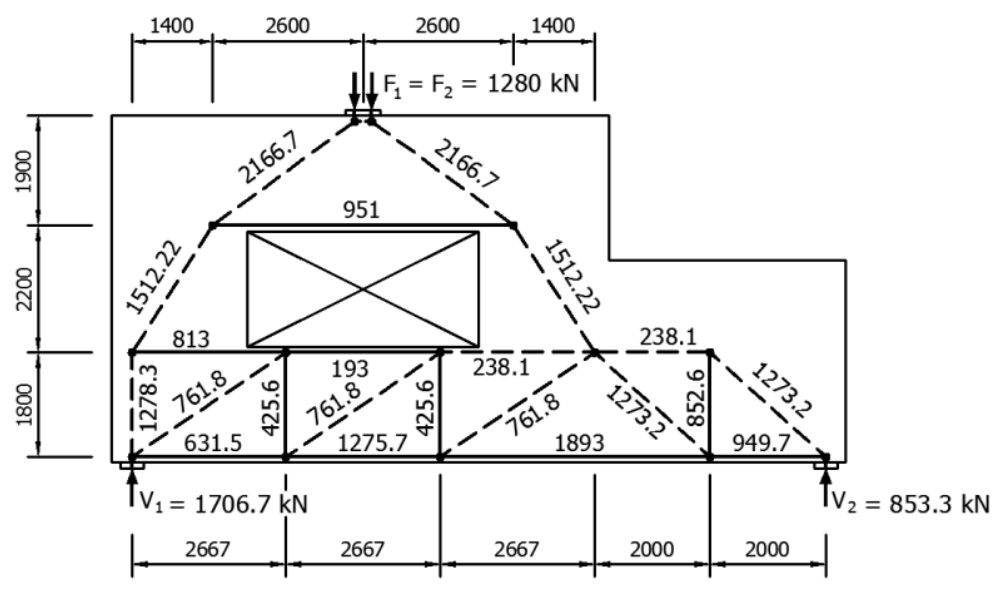

Fig. 6. Computed model forces $(\mathrm{kN})$ assuming yielding of tie $T_{2}$ reinforcement 
Similar to node 1 , the bearing stress is safe and the nominal strength of the strut $C_{2}, C_{2 n}=2132 \mathrm{kN}$. Since $C_{2}=2166.7 \mathrm{kN}$; hence, $\boldsymbol{C}_{2 \boldsymbol{n}}=0.984 \boldsymbol{C}_{\mathbf{2}}$.

\section{Nodes 3 and 4:}

The two nodes need not be checked, since they are smeared nodes, and "the reinforcing bars passing through the nodes are extended beyond the nodal zones and they have sufficient anchorage length." Hence, the strength of the struts connected with these nodes is governed by either the strength of the other connecting nodes or the strength of these struts.

\section{Node 5:}

The width of the tie $T_{2}, w_{T_{2}}=181 \mathrm{~mm}$, and assuming that the width of the prismatic strut $C_{7}$ is equal to the width of the bearing plate at node 14, $w_{C_{7}}^{5}=w_{C_{7}}^{14}=400 \mathrm{~mm}$, and the angle of inclination of the strut $C_{3}, \theta_{3}=58.0^{\circ}$, the width of the strut $C_{3}$, $w_{C_{3}}^{5}=400 \sin \theta_{3}+181 \cos \theta_{3}=435.13 \mathrm{~mm}$. Then, the nominal strength of the strut, $C_{3 n}=19.76 \# \times$ $435.13 \times 305=2622.47 \mathrm{kN}$ (\# the smaller of the node strength and the strut strength), which is greater than the strut force, $C_{3}=1512.22 \mathrm{kN}$.

The width of the vertical strut $C_{7}, w_{C_{7}}^{4}=400 \mathrm{~mm}$. Hence, its nominal strength, $C_{7 n}=21.08 \# \times 400 \times$ $305=2571.76 \mathrm{kN}$ (\# the smaller of the node strength and the strut strength), which is greater than the strut force, $C_{7}=1278.3 \mathrm{kN}$.

\section{Node 6:}

The width of the tie $T_{2}, w_{T_{2}}=181 \mathrm{~mm}$ and of tie $T_{4}$, $w_{T_{4}}=2315 \mathrm{~mm}$, and the angle of inclination of the strut $C_{8}, \theta_{8}=34.0^{\circ}$; Hence; the width of the strut $C_{8}, w_{C_{8}}^{6}=2315 \sin \theta_{8}+181 \cos \theta_{8}=1444.6$ $\mathrm{mm}$. Then, the nominal strength of the strut $C_{8 n}=$ $15.81 \# \times 1444.6 \times 305=6965.93 \mathrm{kN}$ (\# the smaller of the node strength and the strut strength), which is greater than the strut force, $C_{8}=761.8 \mathrm{kN}$.

\section{Node 7:}

Similar to node $6, C_{9 n}=6965.93 \mathrm{kN}$, greater than $C_{9}=761.8 \mathrm{kN}$. For strut $C_{5}, w_{C_{5}}^{7}=181 \mathrm{~mm}$, the nominal strength of the strut $C_{5 n}=f_{c e}^{n} \times w_{C_{5}}^{7} \times \mathrm{b}$ $+A_{s}^{\prime} f_{\mathrm{y}}=(15.81 \times 181 \times 503)+(4 \times 490.87 \times 414)=$
$2252.27 \mathrm{kN}$, which is greater than the strut force, $C_{5}=238.1 \mathrm{kN}$.

\section{Node 8:}

This is a smeared node and hence there is no need to check it. Hence, the strength of the struts connected with this node is governed by either the strength of the other connecting nodes or the strength of these struts.

\section{Node 9:}

This is also a smeared node and hence there is no need to check it, provided that the reinforcement of the tie $T_{6}$ is adequately anchored.

\section{Node 10:}

Since the bearing stress has been checked before, there is no need to check it again. The width of the tie $T_{10}, w_{T_{10}}=266 \mathrm{~mm}$. For strut $C_{12}$, its inclination angle $\theta_{12}=42.0^{\circ}$, which gives a width of the strut $w_{C_{12}}^{10}=400 \sin \theta_{12}+266 \cos \theta_{12}=465.3 \mathrm{~mm}$. Then, the nominal strength of the strut $C_{12 n}=$ $19.76 \# \times 465.3 \times 305=2804.4 \mathrm{kN}$ (\# the smaller of the node strength and the strut strength), which is greater than the strut force, $C_{12}=1273.2 \mathrm{kN}$.

\section{Nodes 11, 12, 13, and 14:}

These nodes have been checked in the same manner and they have sufficient strength.

\subsubsection{Results}

From the obtained results the model elements are all safe except elements $C_{1}$ and $C_{2} \quad$ (similar elements) $C_{1 n}=C_{2 n}=0.984 C_{1}=0.984 C_{1}$. Therefore, the load $P$ should be reduced to $98.4 \%$ of the calculated value; i.e., the predicted collapse load from the STM, $P_{S T M}=0.984 \times 2560=2519 \mathrm{kN}$. Upon checking the skin reinforcement, it is found that all the bottle-shaped struts have adequate transverse reinforcement to resist the transverse tension, as assumed.

\subsection{Nonlinear finite element analysis}

Both linear and nonlinear analyses have been conducted for the specimen under the applied concentrated load only. The right support is prevented from translation in the $\mathrm{y}$ - and $\mathrm{x}$ directions, but the left support is prevented from 
translation in the y-direction only. The objective of the linear analysis was to obtain the stress trajectories that guide to construct of the strut-andtie model. On the other hand, the nonlinear analysis has been performed to obtain the displacement, strains, and stresses at different load levels. The stress trajectories obtained from the linear elastic analysis are illustrated in Fig. 7a and the results obtained from the NFEA are presented in Figs. 7b to $7 \mathrm{~d}$.
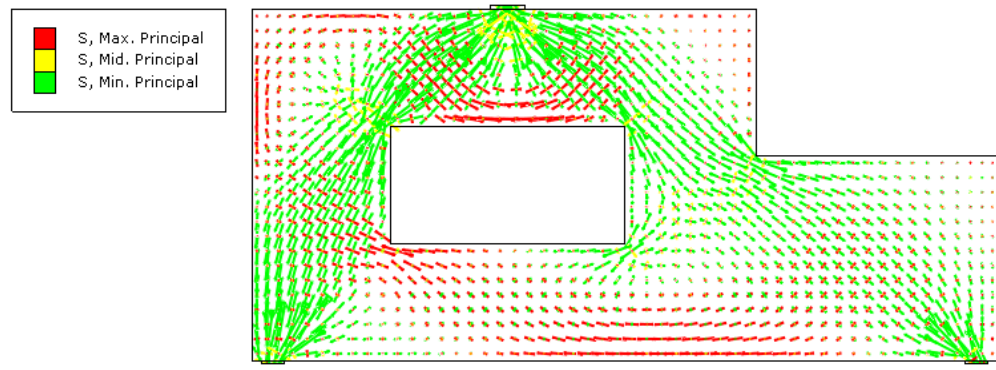

(a) stress trajectories
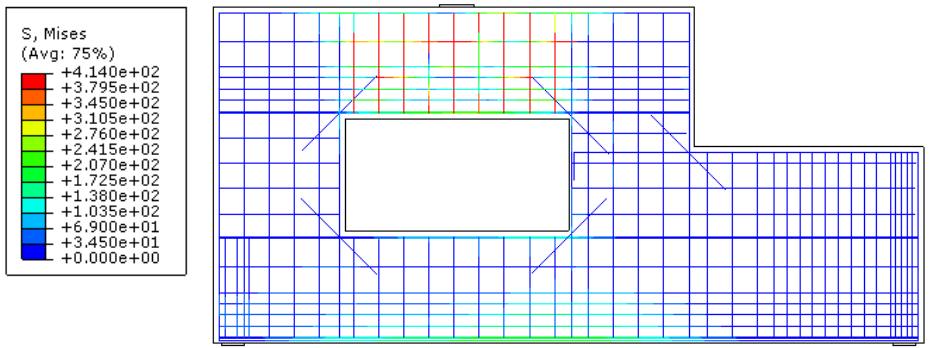

(b) yielding stress zones
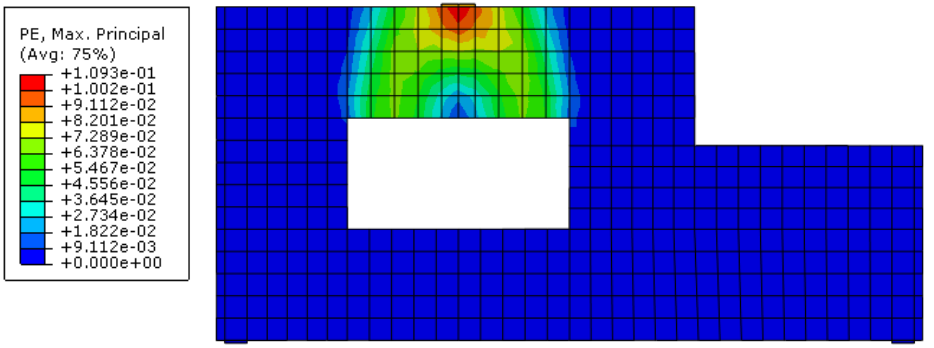

(c) concrete plastic strain distribution

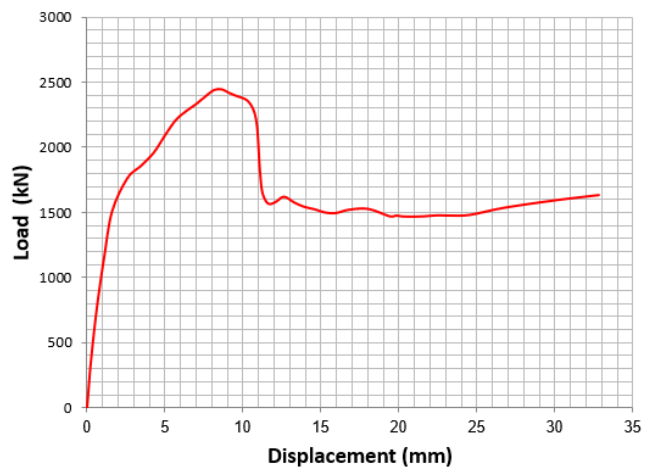

(d) load-displacement curve

Fig. 7. Finite element results of the deep beam with large opening and recess

As observed from the yielding stress zones of the reinforcement and the concrete plastic strain distribution in Figs. $7 \mathrm{~b}$ and $7 \mathrm{c}$, respectively, the failure mode of the beam is a concrete crushing 
failure (shear failure). The main cause of failure was the crushing of the struts below the loading plate and the yielding of the web reinforcement, which indicates that the part of the beam above the opening behaves as a deep beam. The maximum concrete compressive stress in the beam near failure was $30 \mathrm{MPa}$. Neither the beam bottom nor the top longitudinal bars below and above the opening reached their yield stress; they reached $300 \mathrm{MPa}$ and $200 \mathrm{MPa}$, respectively. Fig. 7d shows the loaddisplacement curve, where the initial part of the curve is approximately linear, indicating the elastic range under a service load of $1334 \mathrm{kN}$. The curve revealed a gentle slope after the initial linear portion and exhibited some ductility at failure. These results comply with the prediction of the strut-andtie model. The predicted failure load from the NFEA is $2437 \mathrm{kN}$.

\subsection{Predicted capacity and required nominal strength}

The strength predicted by the STM and the NFEA is given in Table 3 along with the nominal load. The prediction from the STM, as expected, is on the safe side. However, the results from the NFEA are closer to the nominal strength.

\section{Continuous deep beams}

\subsection{Description}

Three full-size normal strength reinforced concrete continuous deep beams (CDB1, CDB2, and CDB3) subjected to concentrated loads at the middle of spans that had been tested by [16] have been selected for comparison between the 2D strut-andtie modeling and the 3D nonlinear finite element analysis. Only the details of the strut-and-tie modeling and the finite element solutions of beam CDB2 are presented here and a summary of the results of the other two beams, $\mathrm{CDB} 1$ and $\mathrm{CDB} 3$, is given at the end of this section. The details of the reinforcement of the tested deep beams are shown in Table 4.

The beam height, $\mathrm{h}=625 \mathrm{~mm}$, depth, $\mathrm{d}=585$ $\mathrm{mm}$, breadth, $\mathrm{b}=120 \mathrm{~mm}$, the width of bearing plates $b_{1}=120 \mathrm{~mm}$, and $b_{2}=b_{3}=250 \mathrm{~mm}$. The shear span, $\mathrm{a}=660 \mathrm{~mm}$. The shear span-to-depth ratio, $a / d=660 / 585=1.12$. The bottom tension steel, $A_{s 1}=452 \mathrm{~mm}^{2}$ and the top tension steel $A_{s 2}=$ $609 \mathrm{~mm}^{2}$. The cylinder compressive strength of concrete, $f_{c}^{\prime}=33.7 \mathrm{MPa}$, the yield stress of longitudinal steel, $f_{\mathrm{y}}=480 \mathrm{MPa}$, the vertical web reinforcement is $A_{s v}=15 \times 2 \mathrm{R} 8$, and the horizontal web reinforcement is $A_{s h}=2 \times 2 \mathrm{R} 8$. The web steel yield stress of mild steel bar R8 is $f_{\mathrm{yv}}=f_{\mathrm{yh}}=370$ MPa.

\subsection{Strut-and-tie modeling of beam CDB2}

Fig. 8 shows the geometry and reinforcement details of the deep beam CDB2, whereas Fig. 9 illustrates the details of its strut-and-model.

Table 3. Strength of the deep beam with large opening and recess

\begin{tabular}{ccccc}
\hline$P_{S T M}(\mathrm{kN})$ & $P_{N F E A}(\mathrm{kN})$ & $P_{n}(\mathrm{kN})$ & $P_{S T M} / P_{n}$ & $P_{\text {NFEA }} / P_{n}$ \\
\hline 2519 & 2437 & 2667 & 0.94 & 0.91 \\
\hline
\end{tabular}

Table 4. Details of considered continuous deep beams

\begin{tabular}{ccccccc}
\hline \multirow{2}{*}{ Beam } & $f_{c}^{\prime}$ & \multirow{2}{*}{$\begin{array}{c}\text { Shear span-to-depth } \\
\text { ratio }(a / d)\end{array}$} & \multicolumn{2}{c}{ Main longitudinal bars } & \multicolumn{2}{c}{ Web reinforcement } \\
\cline { 3 - 6 } & $(\mathrm{MPa})$ & Bottom & Top & Horizontal & Vertical \\
\hline CDB1 & 30.6 & 1.12 & $4 \mathrm{~T} 12$ & $4 \mathrm{~T} 12+2 \mathrm{~T} 10$ & $8 \mathrm{R} 8$ & $29 \mathrm{R} 8$ \\
CDB2 & 33.7 & 1.12 & $4 \mathrm{~T} 12$ & $4 \mathrm{~T} 12+2 \mathrm{~T} 10$ & $4 \mathrm{R} 8$ & $15 \mathrm{R} 8$ \\
CDB3 & 22.4 & 1.12 & $4 \mathrm{~T} 12$ & $4 \mathrm{~T} 12+2 \mathrm{~T} 10$ & $4 \mathrm{R} 8$ & - \\
\hline
\end{tabular}




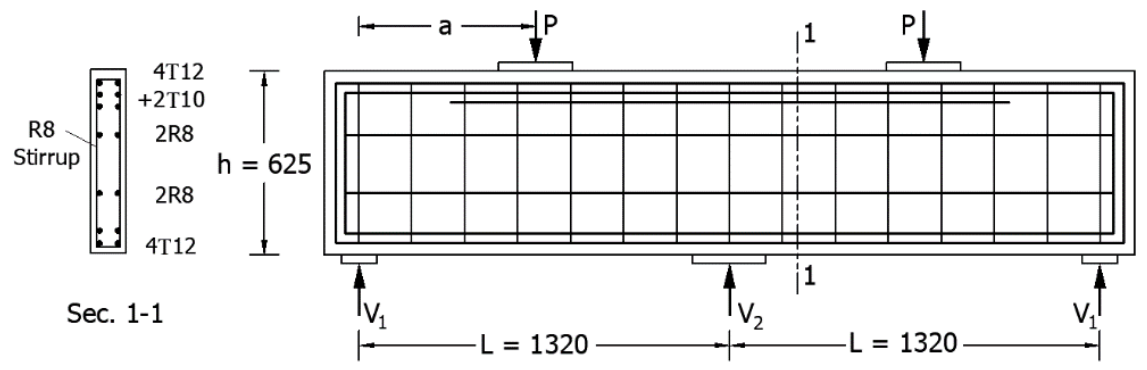

Fig. 8. Reinforcement details and geometry of the beam CDB2

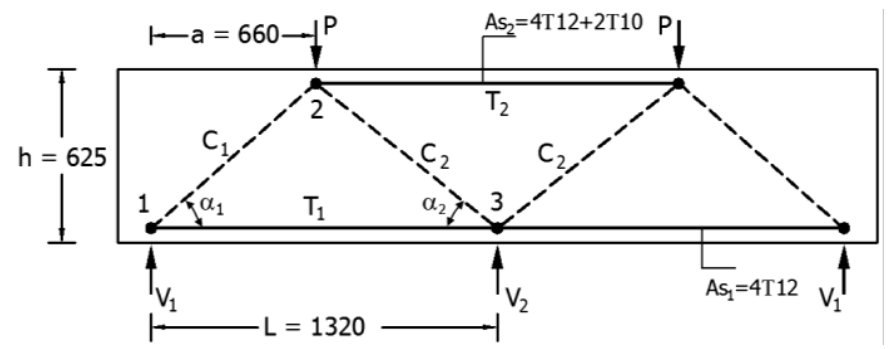

(a) model

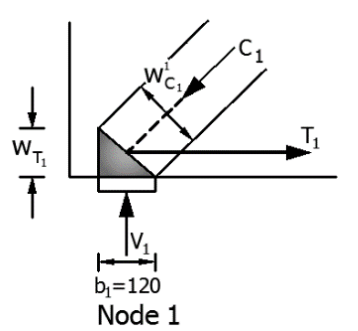

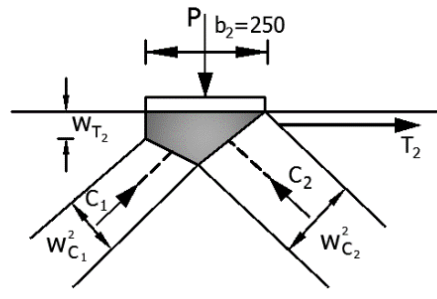

Node 2

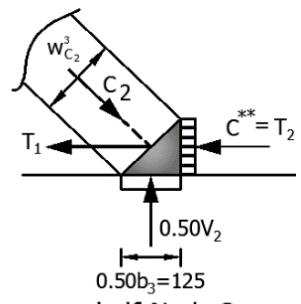

half Node 3

(b) details of nodes 1,2, and half node 3

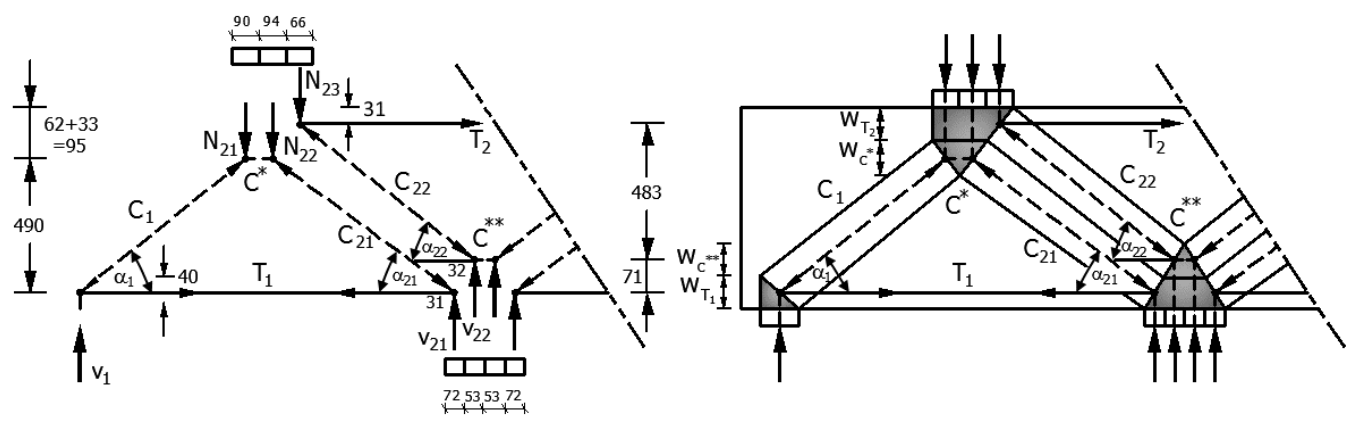

(c) refined STM model

Fig. 9. Details of STM for the continuous deep beam CDB2

\subsubsection{Geometrical parameters}

With reference to Fig. 9, the solution procedure starts with assuming some geometrical parameters. Since the reinforcement detailing allows the use of extended nodal zones, the height of node $1, w_{T_{1}}$, $w_{T_{1}}=2(t-d)=2(625-585)=80 \mathrm{~mm}$, or
$w_{T_{1}}=2\left(c+\emptyset_{\text {stirrup }}\right)+n \emptyset_{\text {bar }}+(n-1) s$

The height of the tie in the upper node, node $2, w_{T_{2}}$, $w_{T_{2}}=2\left(c+\emptyset_{\text {stirrup }}\right)+n \emptyset_{\text {bar }}+(n-1) s=90 \mathrm{~mm}$ The lever $\operatorname{arm} L_{d}$ is

$L_{d}=\mathrm{d}-0.5 \times w_{T_{2}}=585-0.5 \times 90=540 \mathrm{~mm}$ 
The angle

$\alpha_{1}=\tan ^{-1} \frac{L_{d}}{a-0.25 b_{2}}=\tan ^{-1} \frac{540}{400-0.25 \times 100}$
$=42.17^{\circ}$

The angle

$$
\begin{aligned}
& \alpha_{2}=\tan ^{-1} \frac{L_{d}}{a-0.25\left(b_{2}+b_{3}\right)} \\
& =\tan ^{-1} \frac{540}{400-0.25(100+100)} \\
& =45.27^{\circ}
\end{aligned}
$$

\subsubsection{Reactions}

From the linear elastic analysis of the beam, the reactions, $V_{1}=0.313 P$ and $V_{2}=1.375 P$.

\subsubsection{Model geometry and forces}

With reference to Fig. 9a and assuming that the tension reinforcement $A_{s 1}$ of tie $T_{1}$ and $A_{s 2}$ of tie $T_{2}$ reach their yield stress,

$T_{1}=A_{s} \times f_{\mathrm{y}}=480 \times(4 \times 113)=217 \mathrm{kN}$

$T_{2}=A_{s} \times f_{\mathrm{y}}=480 \times(4 \times 113+2 \times 78.5)=292.4 \mathrm{kN}$

The strut force $C_{1}=T_{1} / \cos \alpha_{1}=292.5 \mathrm{kN}$

The reaction $V_{1}=C_{1} \sin \alpha_{1}=196.1 \mathrm{kN}$

Since $V_{1}=0.3125 \mathrm{P}$ from linear elastic analysis, the load $\mathrm{P}$ is then $\mathrm{P}=V_{1} / 0.3125=627.7 \mathrm{kN}$. Then, $V_{2}=1.375 \mathrm{P}=863 \mathrm{kN}$.

From the equilibrium of node 3 , the strut force $C_{2}=0.5 V_{2} / \sin \alpha_{2}=607.4 \mathrm{kN}$.

From the equilibrium of node 2, the tie force $T_{2}$ $=C_{2} \cos \alpha_{2}-C_{1} \cos \alpha_{1}=210.5 \mathrm{kN}$, which is less than the previously calculated value assuming yielding of the tie reinforcement.

\subsubsection{Effective concrete strength of the struts}

The effective concrete strength of strut, $f_{c e}^{s}=$ $0.85 f_{c}^{\prime} \beta_{s}$.

For a prismatic strut,

$f_{c e}^{S}=0.85 \times 33.7 \times 1.0=28.645 \mathrm{MPa}$.

For a strut of bottle-shaped stress field,

$f_{c e}^{s}=0.85 \times 33.7 \times 0.6^{*}=17.187 \mathrm{MPa},(*$ to be verified).

\subsubsection{Effective concrete strength of the struts}

The effective concrete strength of a node,

$f_{c e}^{n}=0.85 f_{c}^{\prime} \beta_{n}$.

For $\mathrm{C}-\mathrm{C}-\mathrm{C}$ node, $f_{c e}^{n}=0.85 \times 33.7 \times 1.0=28.645 \mathrm{MPa}$

For C-C-Tnode, $f_{c e}^{n}=0.85 \times 33.7 \times 0.80=22.916 \mathrm{MPa}$

\subsubsection{Check the bearing of the nodes}

For node 1, the nominal value of the reaction $V_{1 n}=$ $22.916 \times 120 \times 120=330.0 \mathrm{kN}$, which is greater than the force $V_{1}, V_{1}=196.1 \mathrm{kN}$.

For node 2, the nominal value of the load $P_{n}=$ $22.916 \times 120 \times 250=687.5 \mathrm{kN}$, which is greater than the force $\mathrm{P}, \mathrm{P}=627.7 \mathrm{kN}$.

For node 3 , the nominal value of the reaction $V_{2 n}=22.916 \times 120 \times 250=687.50 \mathrm{kN}$, less than the force $V_{2}, V_{2}=863.0 \mathrm{kN}$. Therefore, the force $V_{2}$ should be reduced to the value of $V_{2 n}$; i.e, $V_{2}=$ $687.5 \mathrm{kN}$.

Hence, the load $\mathrm{P}$ is reduced to $\mathrm{P}=V_{1}+0.5 V_{2}=$ $539.85 \mathrm{kN}$ and the strut force $C_{2}$ is subsequently reduced to $C_{2}=483.9 \mathrm{kN}$. The force in the tie $T_{2}$ is further reduced to $T_{2}=123.6 \mathrm{kN}$.

5.2.7. Refinement of the model geometry and forces

Regarding Fig. 9b, the height of the tension tie $T_{2}$, $w_{T_{2}}$ at node 2 should not exceed a value $w_{T_{2} \text { max }}=$ $T_{2} / f_{c e}^{n} b=123.6 \times 1000 / 22.916 \times 120=44.94$ $\mathrm{mm}$; therefore, consider $w_{T_{2}} \approx 45 \mathrm{~mm}$. The width of the prismatic strut $C^{*}$, in Fig. 9c, $w_{C^{*}}$, can be obtained as $C^{*}=T_{1}=217 \mathrm{kN}=f_{c e}^{S} \times w_{C^{*}} \times \mathrm{b}=$ $28.645 \times w_{C^{*}} \times 120$, giving $w_{C^{*}}=63.13 \mathrm{~mm} \approx 66$ $\mathrm{mm}$.

The strut $C_{2}$ is split into two components $C_{21}$ and $C_{22}$. This will lead to the detailed STM shown in Fig. 9c, with geometrical relations and forces calculated upon applying equilibrium at the nodes.

\section{First Trial STM:}

Regarding Fig. 9c, the solution will start by assuming that the width of the force $N_{21}=$ $V_{1} \times 250 / P=196.1 \times 250 / 539.85 \approx 92 \mathrm{~mm}$ and the width of force $N_{22}=N_{23}=79 \mathrm{~mm}$. Also, the width of either force $V_{21}$ or $V_{22}$, is $250 / 4=62.5$ $\mathrm{mm}$. Thus, the values of $\alpha_{1}=41.1^{\circ}, \alpha_{21}=42.17^{\circ}$, and $\alpha_{22}=42.63^{\circ}$ and the force $C^{*}=T_{1}=217 \mathrm{kN}$, then, from horizontal equilibrium at the nodes, $C_{1}=$ $288 \mathrm{kN}$ and $C_{21}=292.8 \mathrm{kN}$. Next, from vertical equilibrium $N_{21}=V_{1}=189.3 \mathrm{kN}$ and $N_{22}=V_{21}=$ $196.6 \mathrm{kN}$. The reaming value of the load is transferred to $N_{23}=V_{21}=0.5 V_{2}-V_{21}=147.15 \mathrm{kN}$, then, the force $C^{* *}=T_{2}=159.9 \mathrm{kN}$ and $C_{22}=217.3$ 
$\mathrm{kN}$ is obtained from horizontal equilibrium and $\mathrm{P}=$ $N_{21}+N_{22}+N_{23}=533 \mathrm{kN}$. Then, a better estimate of the height of the tension tie $T_{2}, w_{T_{2}}$, at node 2 can be calculated, $w_{T_{2} \max }=T_{2} / f_{c e}^{n} b=(159.9 \times 1000) /$ $(22.916 \times 120)=58.1 \mathrm{~mm}$; therefore, consider $w_{T_{2}} \approx$ $62 \mathrm{~mm}$. The STM will be updated leading to the second trial STM.

\section{Second Trial STM:}

As illustrated before, the width of the force $N_{21}=$ $189.3 \times 250 / 533 \approx 90 \mathrm{~mm}$, the width of the force $N_{22}=196.6 \times 250 / 533 \approx 94 \mathrm{~mm}$, and the width of force $N_{23}=66 \mathrm{~mm}$. Also, the width of the force $V_{21}$ $=196.6 \times 250 / 2(196.6+147.15) \approx 72 \mathrm{~mm}$ and the width of the force $V_{22}=53 \mathrm{~mm}$. Finally, the values of $\alpha_{1}=40.2^{\circ}, \alpha_{21}=41.48^{\circ}$, and $\alpha_{22}=$ $41.73^{\circ}$, are obtained and the force $C^{*}=T_{1}=217$ $\mathrm{kN}$. Then, from horizontal equilibrium at the nodes, $C_{1}=284.1 \mathrm{kN}$ and $C_{21}=289.6 \mathrm{kN}$. Next, from vertical equilibrium, $N_{21}=V_{1}=183.4 \mathrm{kN}$ and $N_{22}=$ $V_{21}=191.9 \mathrm{kN}$. The remaining part of the load is transferred to $N_{23}=V_{21}=151.9 \mathrm{kN}$, then, the force $C^{* *}=T_{2}=170.3 \mathrm{kN}$ and $C_{22}=228.2 \mathrm{kN}$ can be obtained from horizontal equilibrium and $\mathrm{P}=\mathrm{N}_{21}+$ $N_{22}+N_{23}=527.2 \mathrm{kN}$.

\subsubsection{Check of stresses}

\section{Node 1:}

Since the bearing stress has been checked before, there is no need to check it again. For strut $C_{1}$, the inclination angle $\alpha_{1}=40.2^{\circ}$, and $w_{C_{1}}^{1}=120 \sin \alpha_{1}$ $+80 \cos \alpha_{1}=138.6 \mathrm{~mm}$. Then, the nominal strength of the strut is $C_{1 n}=17.187 \# \times 120 \times 138.6=285.8$ $\mathrm{kN}$ (\# the smaller of the node strength and the strut strength), which is greater than the strut force.

\section{Node 2:}

Since the bearing stress has been checked before, there is no need to check it again.

For sub-node 21, the width of the strut $C_{1}, w_{C_{1}}^{21}=$ $90 \sin \alpha_{1}+66 \cos \alpha_{1}=108.5 \mathrm{~mm}$. Then, the nominal strength of the strut is $C_{1 n}=17.187 \# \times 120$ $\times 108.5=223.7 \mathrm{kN}$ (\# the smaller of the node strength and the strut strength), which is less than the strut force, $C_{1 n}=0.787 C_{1}$. There is no need to check the prismatic strut $C^{*}$ since this was considered during the estimate of the height of this sub-node.

For sub-node 22, the width of the strut $C_{21}$, $w_{C_{21}}^{22}=94 \sin \alpha_{21}+66 \cos \alpha_{21}=111.7 \mathrm{~mm}$. Then, the nominal strength of the strut is $C_{21 n}=17.187 \#$ $\times 120 \times 111.7=230.4 \mathrm{kN}$ (\# the smaller of the node strength and the strut strength), which is less than the strut force, $C_{21 n}=0.795 C_{1}$.

For sub-node 23, the width of the strut $C_{22}$, $w_{C_{22}}^{23}=66 \sin \alpha_{22}+62 \cos \alpha_{22}=90.2 \mathrm{~mm}$. Then, the nominal strength of the strut is $C_{22 n}=17.187 \#$ $\times 120 \times 90.2=186 \mathrm{kN}$ (\# the smaller of the node strength and the strut strength), which is less than the strut force, $C_{22 n}=0.815 C_{22}$.

Node 3:

For sub-node 31 , the width of the strut $C_{21}$, $w_{C_{21}}^{31}=72 \sin \alpha_{21}+80 \cos \alpha_{21}=107.6 \mathrm{~mm}$. Then, the nominal strength of the strut is $C_{21 n}=17.187 \#$ $\times 120 \times 107.6=222 \mathrm{kN}$ (\# the smaller of the node strength and the strut strength), which is less than the strut force, $C_{21 n}=0.766 C_{21}$.

For sub-node 32 , the width of the strut $C_{22}$, $w_{C_{22}}^{32}=53 \sin \alpha_{22}+62 \cos \alpha_{22}=81.5 \mathrm{~mm}$. Then, the nominal strength of the strut is $C_{22 n}=17.187 \#$ $\times 120 \times 81.5=168.2 \mathrm{kN}$ (\# the smaller of the node strength and the strut strength), which is less than the strut force, $C_{22 n}=0.737 C_{22}$.

\subsubsection{Results}

The nominal strength of the strut $C_{2}$ that consists of $C_{21 n}$ and $C_{22 n}$ is $[(0.766 \times 289.6)+(0.737 \times 228.2)]$ $=390 \mathrm{kN}$. According to the ACI 318-14 [6], the resultant force is assumed to spread at a slop 2 longitudinally and 1 transverse. Hence, the sum of the transverse forces of the strut is $195 \mathrm{kN}$. The skin reinforcement of the beam within the strut length is 2 horizontal bars per face, which can resist a force of $2 \times 2 \times 50.26 \times 370 \times \sin 41.48=49.3 \mathrm{kN}$ perpendicular to the crack and 3 vertical bars per face, which can resist a force of $2 \times 3 \times 50.26 \times 370$ $\times \sin 48.52=83.6 \mathrm{kN}$ perpendicular to the crack. This makes a total of $49.3+83.6=132.9 \mathrm{kN}$, which is less than the required force, $195 \mathrm{kN}$, which indicates that the transverse reinforcement doesn't satisfy the strut requirement. Hence, the assumed 
value $\beta_{s}=0.60$ in the calculation procedure is correct.

The load $\mathrm{P}=N_{21}+N_{22}+N_{23}=527.2 \mathrm{kN}$, which is less than the nominal value at the loading nodes, which is also safe from bearing, $P_{n}=687.5 \mathrm{kN}$. From the obtained results the critical members are $C_{1 n}=0.787 C_{1}, \quad C_{21 n}=0.766 C_{21}$, and $C_{22 n}=$ $0.737 C_{22}$, while the other members attain nominal strength greater than their forces. Therefore, the load components should be reduced to a value of $P$ $=0.787 \times 183.4+0.766 \times 191.9+0.737 \times 151.9=403.3$ $\mathrm{kN}$. Thus, the STM nominal strength, $2 P=806.6$ $\mathrm{kN}$. Since the measured collapse load was $2 \mathrm{P}=950$ $\mathrm{kN}$; then, the STM solution is $85 \%$ of the value measured in the test.

\subsection{Nonlinear finite element analysis of deep beam $C D B 2$}

Beam CDB2 has been analyzed under the two applied concentrated loads at mid-spans and only the middle support is prevented from translation in the $y$ - and $x$-directions, but the external supports are prevented from translation in y-direction only. Both linear and nonlinear analyses have been performed for the beam. The stress trajectories obtained from the linear elastic analysis are illustrated in Fig. 10a and the results obtained from the nonlinear analysis are presented in Figs. 10b-d.

The results of the NFEA, Figs. $10 \mathrm{~b}$ and 10c, illustrate a major diagonal crack in the intermediate shear span of the beam, as in the experimental observations, Fig. 10d. The failure occurred in the interior shear spans between the loading points and middle support. The maximum concrete compressive stresses in the beam CDB2 near failure were $33 \mathrm{MPa}$. Neither the bottom nor the top longitudinal bars reached yield; they were $360 \mathrm{MPa}$ and $150 \mathrm{MPa}$, respectively; but the vertical web reinforcement almost reached its yield strength. The predicted failure load from the 3D nonlinear finite element analysis was $2 \mathrm{P}=860 \mathrm{kN}$, which is about $91 \%$ of the measured value in the test.

\subsection{Predicted capacity and test}

The strength predicted by the STM and the NFEA is given in Table 5 along with the experimental values. The prediction from the STM, as expected, is on the safe side. On the other hand, the results from the NFEA are closer to the measured strength.

\section{Continuous deep beams with large openings}

\subsection{Description}

Two full-scale continuous reinforced concrete deep beams with large openings, specimens $A$ and $B$, subject to two concentrated loads at mid-spans tested by [17] were selected for the comparison between the two-dimensional strut-and-tie modeling and the 3D nonlinear finite element analysis, Figs. 11 and 12. The two specimens have identical overall dimensions and loading arrangement, albeit, different sized openings. The opening is $200 \times 200 \mathrm{~mm}$ in specimen $A$ and $400 \times$ $200 \mathrm{~mm}$ in specimen $B$. Only specimen $B$ is presented here with details and the results of the other beam will be given at the end of this section.

With reference to Fig. 12, the beam height, $h=$ $750 \mathrm{~mm}$, depth, $d=705 \mathrm{~mm}$, breadth, $b=180 \mathrm{~mm}$, the width of bearing plates $b_{1}=150 \mathrm{~mm}$, and $b_{2}=$ $b_{3}=200 \mathrm{~mm}$. The shear span, $a=1000 \mathrm{~mm}$. The shear span-to-depth ratio, $a / d=1000 / 705=1.41$. The tension steel, $A_{s 1}=A_{s 2}=628.3 \mathrm{~mm}^{2}$. The concrete cylinder strength, $f_{c}^{\prime}=27.7 \mathrm{MPa}$. High strength deformed steel bars, with yield stress, $f_{\mathrm{y}}=$ $460 \mathrm{MPa}$, and mild steel bar with a nominal yield stress, $f_{\mathrm{y}}=250 \mathrm{MPa}$. The vertical and horizontal web reinforcement is as shown in the figures.

In addition to the reinforcements required at the tie positions, confining reinforcement was incorporated to improve the strength of nodes where potentially high compressive stresses were encountered. Confining reinforcement was used below the concentrated loads, above the supports, and around the openings, Fig. 12. 
S, Max. Principal

S, Mid. Principal

S, Min. Principal

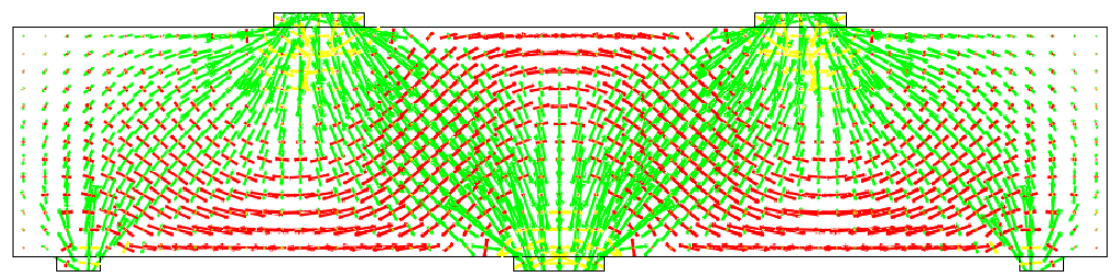

(a) stress trajectories
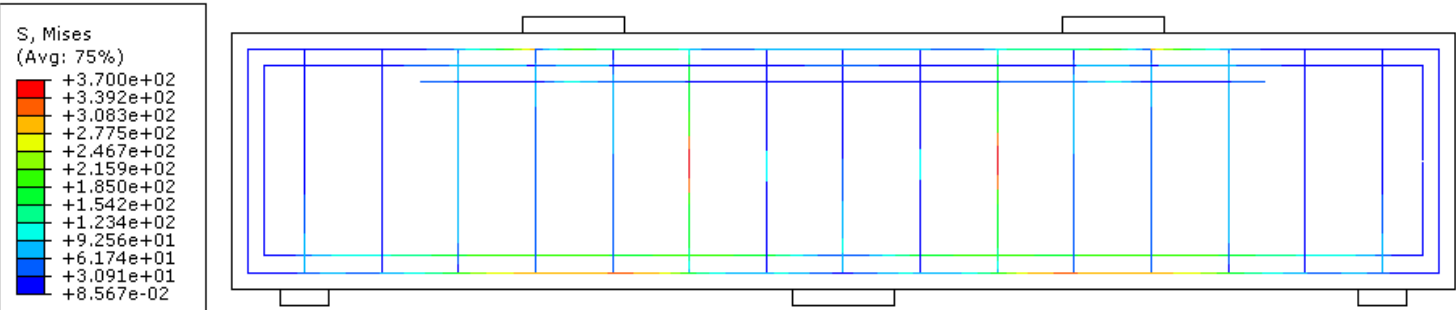

(b) yielding stress zones
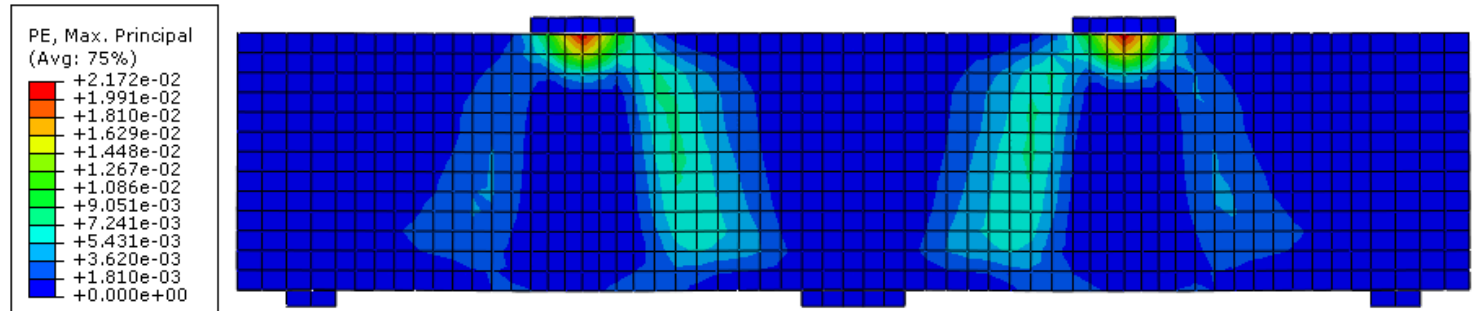

(c) concrete plastic strain distribution

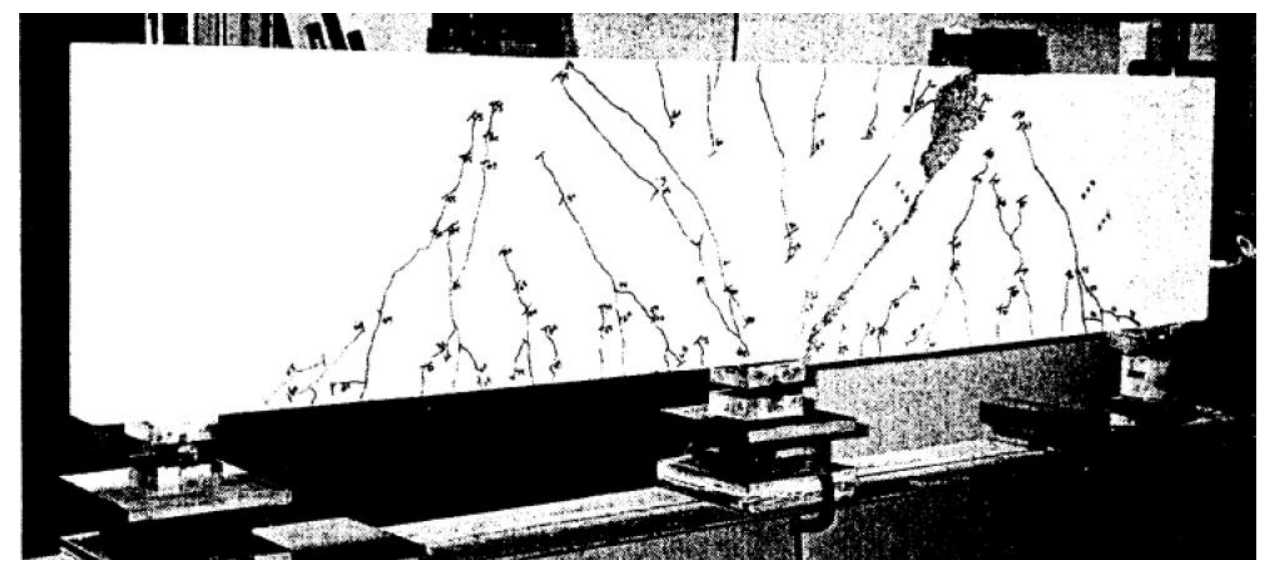

(d) experimental cracking patterns at the ultimate test load

Fig. 10. Finite element results of the continuous CDB2

Table 5. Strength of continuous deep beam examples

\begin{tabular}{lcccccc}
\hline Specimen & $f_{c}^{\prime}(\mathrm{MPa})$ & $P_{S T M}(\mathrm{kN})$ & $P_{\text {NFEA }}(\mathrm{kN})$ & $P_{\text {Test }}(\mathrm{kN})$ & $P_{\text {STM }} / P_{\text {Test }}$ & $P_{\text {NFEA }} / P$ \\
\hline CDB1 & 30.6 & 455.8 & 500 & 550 & 0.83 & 0.91 \\
CDB2 & 33.7 & 403.3 & 430 & 475 & 0.85 & 0.91 \\
CDB3 & 22.4 & 260.3 & 260 & 285 & 0.91 & 0.91 \\
\hline
\end{tabular}




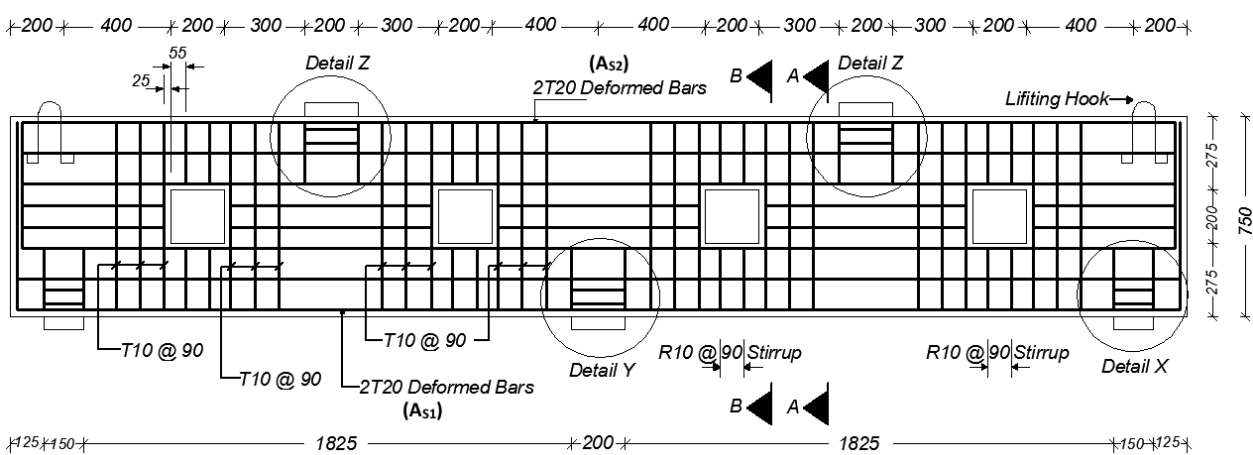

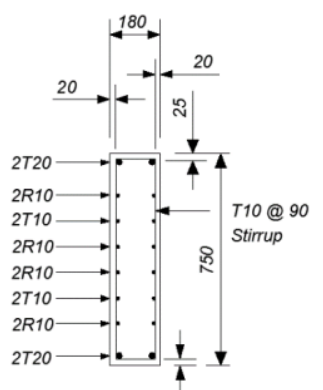

$A-A^{2}$

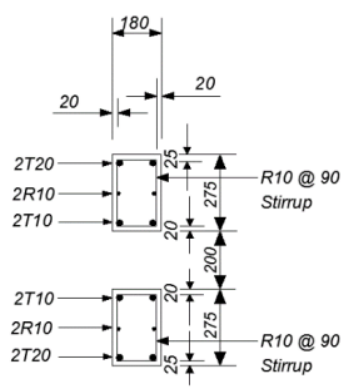

B-B

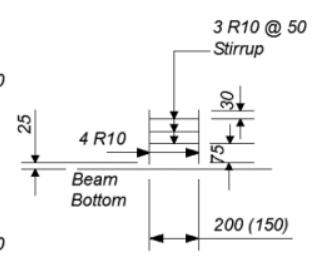

Detail Y

(Detail X)

Fig. 11. Continuous deep beam with openings, specimen $A$

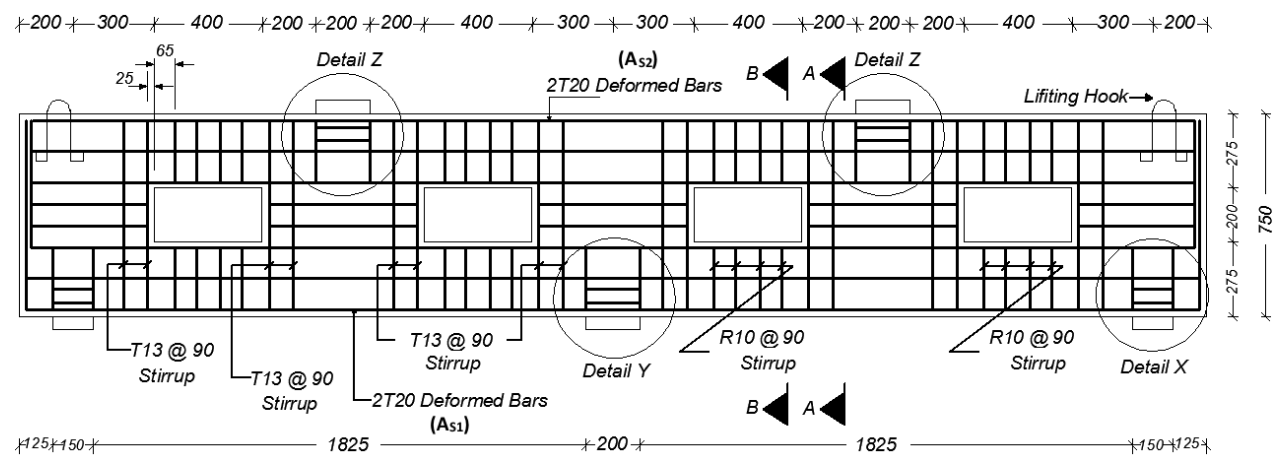

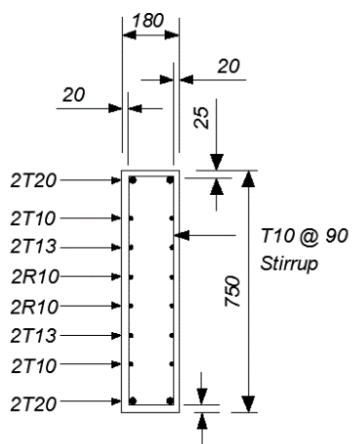

A-A

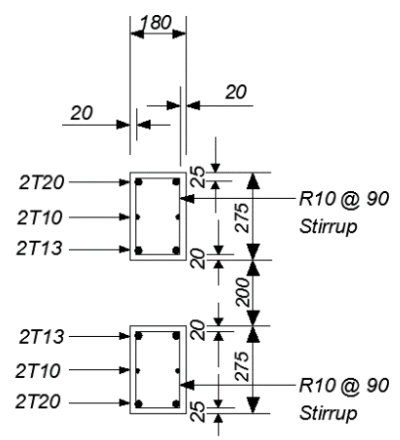

B-B

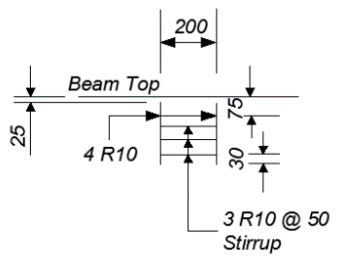

Detail Z

Fig. 12. Continuous deep beam with openings, specimen $B$ 
To eliminate potentially the detrimental effects of apparently inadequate reinforcing details on loadcarrying capacity, the reinforcing bars passing the nodes were extended beyond the nodal zones and the bottom longitudinal reinforcing bars were extended into the end supports and were anchored using standard 180-degree hooks.

\subsection{Strut-and-tie modeling of specimen $B$}

\subsubsection{Geometrical parameters}

From the stress pattern obtained from the linear elastic analysis, Fig. 15a, it is obvious how the struts go around the openings to transfer their forces to the supports. In addition, the connecting ties maintaining equilibrium are logical and adhere to the reinforcement details. Thus, developing an STM of the beam becomes a straightforward matter. For, the proposed STM, shown in Fig. 13, the numbering of ties and struts is illustrated on the left part of the model and the numbering of the nodes is illustrated on the right part.

With reference to Fig. 13, the reinforcement of each of the ties $T_{1}, T_{2}$, and $T_{13}$ are 2T20. Since the reinforcement details allow the use of extended nodal zones, the width of each of these ties, the height of nodes 1, 2, 11 and 15, are as follows,

$w_{T_{1}}=w_{T_{2}}=2(t-d)=2(750-705)=90 \mathrm{~mm}$,

or

$w_{T_{1}}=w_{T_{2}}=2\left(c+\emptyset_{\text {stirrup }}\right)+n \emptyset_{\text {bar }}+(n-1) s$
Each of the ties $T_{1}, T_{2}$, and $T_{13}$ has a nominal strength, $T_{1 n}=T_{2 n}=T_{13 n}=460 \times 628.3=289 \mathrm{kN}$. Each of the ties $T_{3}, T_{6}, T_{8}$ and $T_{11}$ is represented by $2 T 13$ (2-legs) vertical stirrups, spaced $90 \mathrm{~mm}$ center to center. The width of each of these ties is

$w_{T_{3}}=w_{T_{6}}=\ldots=2 c+n \emptyset_{\text {bar }}+(n-1) s=166 \mathrm{~mm}$.

The nominal strength of each of the ties $T_{3}, T_{6}, T_{8}$ and $T_{11}$ is

$T_{3 n}=T_{6 n}=\ldots=A_{s} \times f_{\mathrm{y}}=(2 \times 2 \times 132.7) \times 460=144.4 \mathrm{kN}$.

In the same manner, each of the ties $T_{4}, T_{5}, T_{7}$, $T_{9}, T_{10}$ and $T_{12}$ are represented by $(2 \mathrm{~T} 13+2 \mathrm{~T} 10)$ horizontal bars with width $143 \mathrm{~mm}$ and nominal strength $194.2 \mathrm{kN}$.

\subsubsection{Reactions}

From linear elastic analysis, $V_{1}=0.3125 P$ and $V_{2}=$ $1.375 P$.

\subsubsection{Model geometry and forces}

In order to obtain the forces in the model elements, the reinforcement of a selected tie is assumed to reach its yield stress. The choice of the tie to start with is up to the designer; however, some elements come to mind at the first glance; e.g., ties $T_{2}$ or $T_{13}$, Fig. 13. Nevertheless, the solution to this problem is initiated by assuming that the reinforcement of tie $T_{10}$ reaches its yield stress, $T_{10}=194.2 \mathrm{kN}$. Then, from simple truss analysis, the model forces are obtained, Fig. 14.

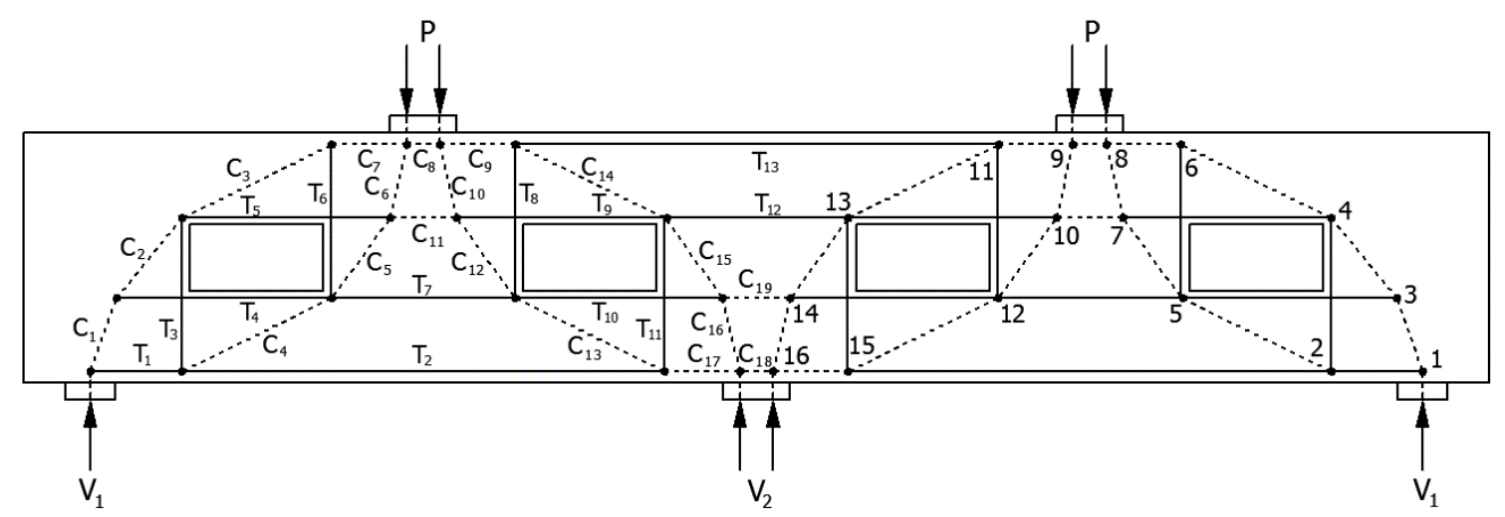

Fig. 13. Proposed strut-and-tie model for specimen $B$ 


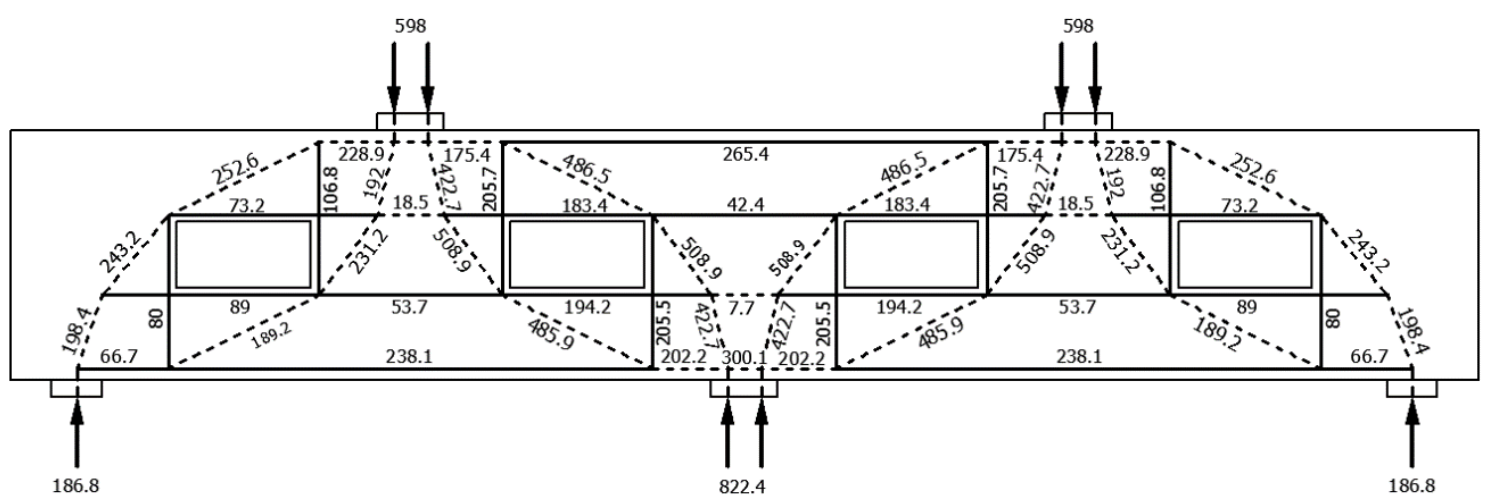

Fig. 14. Computed model forces $(k N)$ assuming yielding of $T_{10}$ reinforcement

6.2.4. Effective concrete strength of the struts

The effective concrete strength of strut,

$f_{c e}^{s}=0.85 f_{c}^{\prime} \beta_{s}$

For prismatic strut,

$f_{c e}^{S}=0.85 \times 27.7 \times 1.0=23.55 \mathrm{MPa}$

For bottle-shaped strut with sufficient reinforcement to resist the transverse tension,

$f_{c e}^{S}=0.85 \times 27.7 \times 0.75=17.66 \mathrm{MPa}$

This value will be used throughout the example and it will be checked later.

\subsubsection{Effective concrete strength of the nodes}

The effective concrete strength of a node,

$f_{c e}^{n}=0.85 f_{c}^{\prime} \beta_{n}$.

For $\mathrm{C}-\mathrm{C}-\mathrm{C}$ node,

$f_{c e}^{n}=0.85 \times 27.7 \times 1.0=23.55 \mathrm{MPa}$.

For $\mathrm{C}-\mathrm{C}-\mathrm{T}$ node,

$f_{c e}^{n}=0.85 \times 27.7 \times 0.80=18.84 \mathrm{MPa}$.

For $\mathrm{C}-\mathrm{T}-\mathrm{T}$ node,

$f_{c e}^{n}=0.85 \times 27.7 \times 0.60=14.13 \mathrm{MPa}$

\subsubsection{Check the bearing of the nodes}

For node 1 , the nominal value of the reaction $V_{1}$, $V_{1 n}=18.84 \times 150 \times 180=508.6 \mathrm{kN}$, which is greater than the reaction, $V_{1}=186.8 \mathrm{kN}$.

For nodes 8 and 9 , the nominal value of the load $P, P_{n}=23.55 \times 200 \times 180=847.6 \mathrm{kN}$, which is greater than the load, $P=598 \mathrm{kN}$.
For node 16, the nominal value of the reaction $V_{2}, V_{2 n}=23.55 \times 200 \times 180=847.6 \mathrm{kN}$, which is greater than the reaction, $V_{2}=822.4 \mathrm{kN}$.

\subsubsection{Check of stresses}

\section{Node 1:}

Since the bearing stress has been checked before, there is no need to check it again. The inclination angle of the strut $C_{1}, \theta_{1}=70.3^{\circ}$, which gives a width of the strut $w_{C_{1}}^{1}=\quad 150 \sin \theta_{1}+$ $90 \cos \theta_{1}=171.5 \mathrm{~mm}$. Then, the nominal strength of the strut $C_{1 n}=17.66 \# \times 171.5 \times 180=545.1 \mathrm{kN}$ (\# the smaller of the node strength and the strut strength), which is greater than the strut force, $C_{1}=$ $198.4 \mathrm{kN}$.

\section{Node 2:}

The width of the tie $T_{2}, w_{T_{2}}=90 \mathrm{~mm}$ and of tie $T_{3}$, $w_{T_{3}}=166 \mathrm{~mm}$, and the angle of inclination of the strut $C_{4}, \theta_{4}=25.0^{\circ}$. Hence, the width of the strut $C_{4}, w_{C_{4}}=166 \sin \theta_{4}+90 \cos \theta_{4}=151.7 \mathrm{~mm}$. Then, the nominal strength of the strut $C_{4 n}=14.13 \#$ $\times 151.7 \times 180=385.7 \mathrm{kN}$ (\# the smaller of the node strength and the strut strength), which is greater than the strut force, $C_{4}=189.2 \mathrm{kN}$.

\section{Nodes 3, 7, 10, and 14:}

These nodes need not be checked, since they are smeared nodes, and "the reinforcing bars passing the nodes are extended beyond the nodal zones and they have sufficient anchorage length." Besides, the strength of the struts connected with these nodes is 
governed by either the strength of the other connecting nodes or the strength of these struts.

\section{Node 4:}

The width of the tie $T_{3}, w_{T_{3}}=166 \mathrm{~mm}$, and of tie $T_{5}$, $w_{T_{5}}=143 \mathrm{~mm}$, and the angle of inclination of the strut $C_{2}, \theta_{2}=50.2^{\circ}$. Hence, the width of the strut $C_{2}, w_{C_{2}}^{4}=166 \sin \theta_{2}+143 \cos \theta_{2}=219 \mathrm{~mm}$. Then, the nominal strength of the strut, $C_{2 n}=$ $14.13 \# \times 219 \times 180=556.8 \mathrm{kN}$ (\# the smaller of the node strength and the strut strength), which is greater than the strut force, $C_{2}=243.2 \mathrm{kN}$.

For strut $C_{3}$, the angle of inclination is $\theta_{3}=25.0^{\circ}$. Then, the width of the strut, $w_{C_{3}}^{4}=166 \sin \theta_{3}+$ $143 \cos \theta_{3}=199.7 \mathrm{~mm}$. Then, the nominal strength of the strut, $C_{3 n}=14.13 \# \times 199.7 \times 180=508 \mathrm{kN}$ (\# the smaller of the node strength and the strut strength), which is greater than the strut force, $C_{3}=$ $252.6 \mathrm{kN}$.

\section{Node 5:}

As for nodes 1, 2, and 4, $w_{T_{6}}=166 \mathrm{~mm}, w_{T_{7}}=143$ $\mathrm{mm}, \theta_{4}=25.0^{\circ}$,

$w_{C_{4}}^{5}=199.7 \mathrm{~mm}, C_{4 n}=508 \mathrm{kN}$, greater than $C_{4}=$ $189.2 \mathrm{kN}$. Also, $\theta_{5}=54.0^{\circ}$,

$w_{C_{5}}^{5}=218.4 \mathrm{~mm}, C_{5 n}=555.2 \mathrm{kN}$, greater than $C_{5}=$ $231.2 \mathrm{kN}$.

\section{Node 6:}

For this node, assuming that the force in the prismatic strut $C_{7}$ is equal to its nominal strength; then, $C_{7}=228.9 \mathrm{kN}=23.55 \times w_{C_{7}} \times 180$, which gives $w_{C_{7}}=54 \mathrm{~mm}$. The width of the tie $T_{6}, w_{T_{6}}=$ $166 \mathrm{~mm}$ and the angle of inclination of the strut $C_{3}$, $\theta_{3}=25.0^{\circ}$. Hence, the width of the strut $C_{3}, w_{C_{3}}^{6}=$ $166 \sin \theta_{3}+54 \cos \theta_{3}=119.1 \mathrm{~mm}$. Then, the nominal strength of the strut, $C_{3 n}=17.66 \# \times 119.1$ $\times 180=378.6 \mathrm{kN}$ (\# the smaller of the node strength and the strut strength), which is greater than the strut force, $C_{3}=252.6 \mathrm{kN}$.

\section{Node 8:}

Since the bearing stress has been checked before, there is no need to check it again. The width of the prismatic strut $C_{8}$ can be obtained upon assuming that the force in the strut is equal to its nominal strength; then, $C_{8}=273.3 \mathrm{kN}=23.55 \times w_{C_{8}} \times 180$, which gives $w_{C_{8}}=64.5 \mathrm{~mm}$. The angle of inclination of the strut $C_{6}$ is $\theta_{6}=76.6^{\circ}$. Hence, the width of the strut $C_{6}, w_{C_{6}}^{8}=100 \sin \theta_{6}+64.5 \cos \theta_{6}$ $=112.2 \mathrm{~mm}$. Then, the nominal strength of the strut, $C_{6 n}=17.66 \# \times 112.2 \times 180=356.6 \mathrm{kN}$ (\# the smaller of the node strength and the strut strength), which is greater than the strut force, $C_{6}=192 \mathrm{kN}$.

\section{Node 9:}

Since the bearing stress has been checked before, there is no need to check it again. The width of the prismatic strut $C_{8}, w_{C_{8}}=64.5 \mathrm{~mm}$, and the angle of the inclination angle of the strut $C_{10}$ is $\theta_{10}=76.6^{\circ}$. Then, the width of the strut $C_{10}, w_{C_{10}}^{9}=100 \sin \theta_{10}$ $+64.5 \cos \theta_{10}=112.2 \mathrm{~mm}$. The nominal strength of the strut $C_{10}$ is then, $C_{10 n}=17.66 \# \times 112.2 \times 180$ $=356.6 \mathrm{kN}$ (\# the smaller of the node strength and the strut strength), which is less than the strut force, $C_{10}=422.7 \mathrm{kN}$; i.e., $C_{10 n}=0.843 C_{10}$.

Node 11:

The width of the tie $T_{8}, w_{T_{8}}=166 \mathrm{~mm}$, and of tie $T_{13}, w_{T_{13}}=90 \mathrm{~mm}$, and the angle of inclination of the strut $C_{14}, \theta_{14}=25.0^{\circ}$. Then, the width of the strut, $w_{C_{14}}^{11}=166 \sin \theta_{14}+90 \cos \theta_{14}=151.7 \mathrm{~mm}$. Then, the nominal strength of the strut, $C_{14 n}=$ $14.13 \# \times 151.7 \times 180=385.7 \mathrm{kN}$ (\# the smaller of the node strength and the strut strength), which is less than the strut force, $C_{14}=486.5 \mathrm{kN}$; i.e., $C_{14 n}$ $=0.793 C_{14}$.

\section{Node 12:}

As for nodes 1, 2, and 3, $w_{T_{8}}=166 \mathrm{~mm}, w_{T_{7}}=143$ $\mathrm{mm}$, the angle of inclination of the strut $C_{12}, \theta_{12}=$ $54.0^{\circ}$, and $w_{C_{12}}^{12}=218.4 \mathrm{~mm}$. The nominal strength of the strut $C_{12}, C_{12 n}=555.2 \mathrm{kN}$, which is greater than the strut force, $C_{12}=508.9 \mathrm{kN}$. As for strut $C_{13}$, the angle of inclination, $\theta_{13}=25.0^{\circ}$, and $w_{C_{13}}^{12}=199.7 \mathrm{~mm}, C_{13 n}=508 \mathrm{kN}$, which is greater than the strut force, $C_{13}=485.9 \mathrm{kN}$.

\section{Node 13:}

As for nodes 1,2 , and $3, w_{T_{11}}=166 \mathrm{~mm}, w_{T_{12}}=$ $143 \mathrm{~mm}$, the angle of inclination of the strut $C_{14}$, $\theta_{14}=25.0^{\circ}$ and $w_{C_{14}}^{13}=199.7 \mathrm{~mm}$. The nominal strength of the strut $C_{14}, C_{14 n}=508 \mathrm{kN}$, which is 
greater than the strut force, $C_{14}=486.5 \mathrm{kN}$. As for strut $C_{15}$, the angle of inclination, $\theta_{15}=54.0^{\circ}$, and $w_{C_{15}}^{13}=218.4 \mathrm{~mm}$; then, $C_{15 n}=555.2 \mathrm{kN}$, which is greater than the strut force, $C_{15}=508.9 \mathrm{kN}$.

\section{Node 15:}

As for nodes 1, 2, and 3, $w_{T_{11}}=166 \mathrm{~mm}, w_{T_{2}}=90$ $\mathrm{mm}$, the angle of inclination of the strut $C_{13}, \theta_{13}=$ $25.0^{\circ}$ and $w_{C_{13}}^{15}=151.7 \mathrm{~mm}$. The nominal strength of the strut $C_{13}, C_{13 n}=385.7 \mathrm{kN}$, which is less than the strut force, $C_{13}=485.9 \mathrm{kN}$; i.e., $C_{13 n}=$ $0.794 C_{13}$.

\section{Node 16:}

Since the bearing stress has been checked before, there is no need to check it again. The width of the prismatic strut $C_{18}$ can be obtained by assuming that the force in the strut is equal to its nominal strength; then, $C_{18}=300.1 \mathrm{kN}=23.55 \times w_{C_{8}} \times 180$, which gives $w_{C_{18}}=70.8 \mathrm{~mm}$. The angle of inclination of the strut $C_{16}, \theta_{16}=76.6^{\circ}$; hence, its width, $w_{C_{16}}^{16}=$ $100 \sin \theta_{16}+70.8 \cos \theta_{16}=113.7 \mathrm{~mm}$. Then, the nominal strength of the strut, $C_{16 n}=17.66^{\#} \times 113.7$ $\times 180=361.4 \mathrm{kN}$, which is less than the strut force, $C_{16}=422.7 \mathrm{kN}$; i.e., $C_{16 n}=0.855 C_{16}$.

\subsubsection{Results}

From the obtained results the model elements are all safe except elements $C_{10}, C_{13}, C_{14}$, and $C_{16}$, with $C_{14}$ the most critical, $C_{14 n}=0.793 C_{14}$. Therefore, the load $P$ should be reduced to $79.3 \%$ of the calculated value; i.e., the predicted collapse load from the STM, $P_{S T M}=0.793 \times 598=$ $474.2 \mathrm{kN}$. Since the measured collapse load was $555 \mathrm{kN}$; then, the predicted collapse load from the STM is $85.4 \%$ of the measured value in the test.

In the preceding calculations, it has been assumed that the bottle-shaped struts have adequate reinforcement to resist the transverse tension, which should be verified. However, with the obtained beam capacity from $S T M$, the forces in all elements have been reduced to $79.3 \%$ of the calculated value, which makes the check unnecessary for all struts that attained nominal strength exceeding their original forces; (the ratio between the strength of struts without transverse reinforcement to that with adequate transverse reinforcement is 0.8). To this, only struts $C_{10}, C_{13}, C_{14}$ and $C_{16}$ need to be checked. Upon checking these latter struts, it was found that they have adequate transverse reinforcement.

\subsection{Nonlinear finite element analysis of specimen B}

The specimen has been analyzed under the two concentrated loads at mid-spans and only the middle support is prevented from translation in the $y$ - and $x$-directions, but the external supports are prevented from translation in the y-direction only. Both linear and nonlinear analyses have been performed for the specimen. The stress trajectories obtained from the linear elastic analysis are illustrated in Fig. 15a and the results obtained from the nonlinear analysis are presented in Figs. $15 \mathrm{~b}$ to $15 \mathrm{~d}$.

As observed from the yielding stress zones and the plastic strain distribution, Figs. $15 \mathrm{~b}$ and c, compression failure of one of the struts was the main cause of failure of the specimen (concrete crushing failure). The failure occurred in the interior shear spans between the loading points and middle support as detected in the experimental crack pattern, Fig 15d. The maximum concrete compressive stress in the specimen B near failure was $27 \mathrm{MPa}$. Neither the bottom nor the top longitudinal bars reached their yield strength; they reached $344 \mathrm{MPa}$ and $270 \mathrm{MPa}$, respectively. As given in the experimental results, the horizontal reinforcement above and below the interior opening yielded. The predicted failure load from the 3D nonlinear finite element analysis of specimen $B$ is $500 \mathrm{kN}$; about $90 \%$ of the measured values.

\subsection{Predicted capacity and test}

In Table 6, the strength predicted by the STM and the NFEA is given along with the measured values. The prediction from the $S T M$, as expected, is on the safe side. However, as in the previous cases, the results from the NFEA are closer to the measured strength. 
S, Max. Principal

S, Mid. Principal

S, Min, Principal

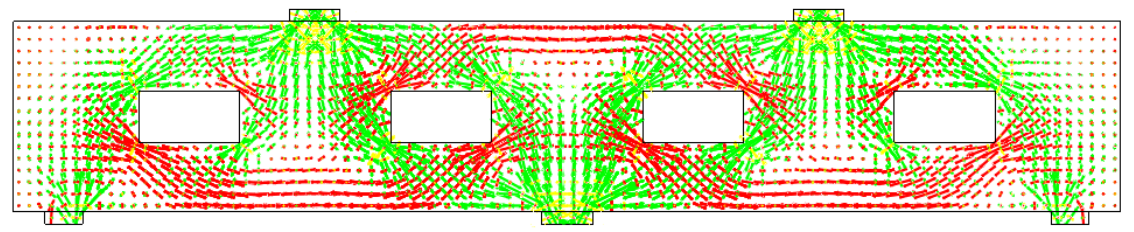

(a) stress trajectories
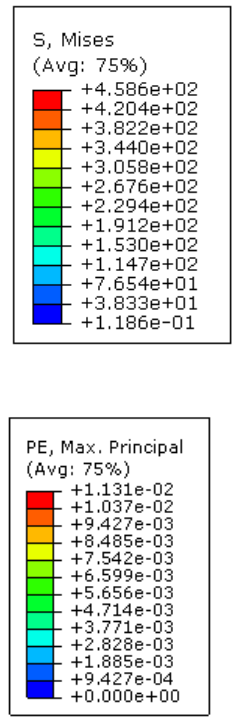

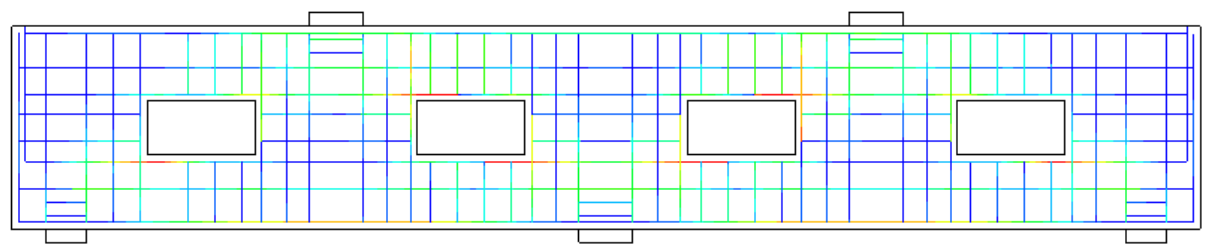

(b) yielding stress zones

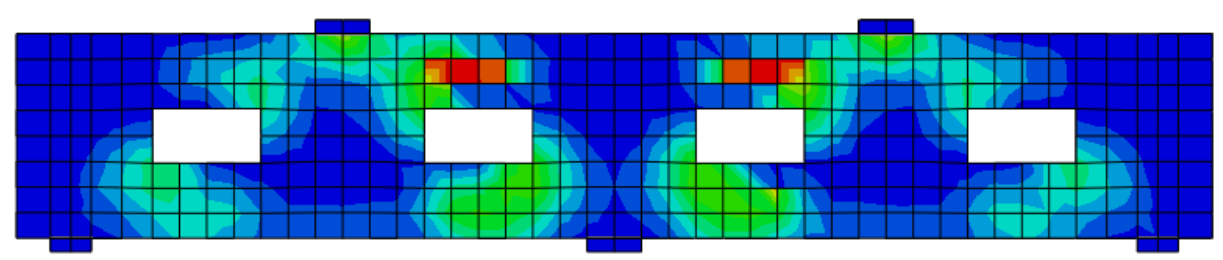

(c) concrete plastic strain distribution

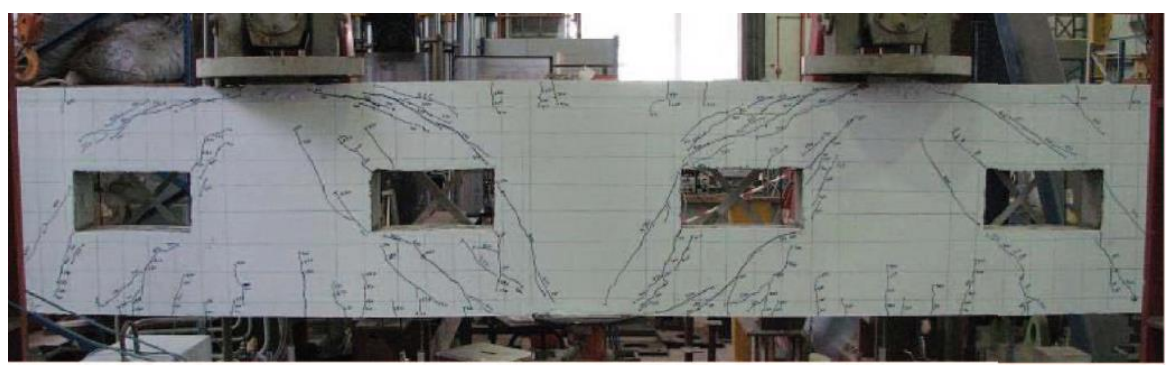

(d) experimental cracking patterns at the ultimate test load

Fig. 15. Finite element results of specimen B

Table 6. Strength of specimens $A$ and $B$ of continuous deep beams with large openings

\begin{tabular}{lcccccc}
\hline Specimen & $f_{c}^{\prime}(\mathrm{MPa})$ & $P_{\text {STM }}(k N)$ & $P_{\text {NFEA }}(k N)$ & $P_{\text {Test }}$ & $P_{\text {STM }} / P_{\text {Test }}$ & $P_{\text {NFEA }} / P_{\text {Test }}$ \\
\hline$A$ & 26.4 & 481.2 & 510 & 565 & 0.85 & 0.90 \\
$B$ & 27.7 & 474.2 & 500 & 555 & 0.85 & 0.90 \\
\hline
\end{tabular}

\section{Ledges of inverted-T beams}

\subsection{Description}

Four full-size normal strength reinforced concrete Inverted-T beams (SS3-42-2.5-06, C1-42-1.85-06,
DC1-42-2.5-03, and SC1-42-1.85-03) with various details of web reinforcement, ledge geometries, number of point loads, and shear-span-to-depth ratio $(\mathrm{a} / \mathrm{d})$ that had been tested by [18] were selected for comparison between the 3D strut-and-tie 
modeling and the 3D nonlinear finite element analysis. Only the details of the strut-and-tie model and the finite element solutions of beam SC1-421.85-03 are presented here and a su mmary of the results of the other three beams is given at the end of this section.

Tables 7 and 8 present details and material properties of the selected beams, where $f_{c}^{\prime}$ is the concrete compressive strength, $f_{\mathrm{y} l}$ is the yield stress of the longitudinal reinforcement, $f_{\mathrm{yv}}$ is the yield stress of the transverse reinforcement, $f_{\mathrm{yh}}$ is the yield stress of the skin reinforcement, and $f_{\text {yha }}$ is the yield stress of the hanger steel. Besides, Table 9 gives the distance from the center of the load to the end of the ledge for three ledge types. Fig. 16 illustrates a summary of the experimental program. More details of the test and material properties can be found in $[18,19]$.
Constant web width of $533 \mathrm{~mm}$ was used for the beams of the experimental program. The width of the ledge was also the same, $267 \mathrm{~mm}$, on each side of the beams. All other dimensions varied between the beams. Figs. 17 and 18 show typical specimen geometries and reinforcing details of the studied Inverted-T beams [18].

\subsection{Strut-and-tie modeling of specimen SC1-42- 1.85-03}

Imperative modifications for both the ACI 318 [14] and AASHTO LRFD Codes [20] particularly for the strength of the nodes and the strength of the strut-to-node interfaces of Inverted-T beams have been recommended by [18, 21, 22]. A brief overview of the STM method and failure criteria, adopted in this study, is presented in this section.

Table 7. Summary of beam details

\begin{tabular}{|c|c|c|c|c|c|c|c|c|c|}
\hline Specimen & $\begin{array}{c}\text { Web } \\
\text { Height } \\
\text { h, (mm) }\end{array}$ & $\begin{array}{l}\text { Ledge } \\
\text { Depth } \\
(\mathrm{mm})\end{array}$ & $\begin{array}{l}\text { Ledge } \\
\text { Length }\end{array}$ & $\begin{array}{l}\text { Load } \\
\text { Point }\end{array}$ & $\begin{array}{c}b_{w}, \\
(\mathrm{~mm})\end{array}$ & $\begin{array}{c}d, \\
(\mathrm{~mm})\end{array}$ & $a / d$ & $\begin{array}{l}\text { Support } \\
\text { Plate } \\
(\mathrm{mm})\end{array}$ & $\begin{array}{l}\text { Load } \\
\text { Plate } \\
(\mathrm{mm})\end{array}$ \\
\hline SS3-42-2.50-06 & 1067 & 356 & Short & 3 & 533 & 956 & 2.50 & $406 \times 508$ & $457 \times 229$ \\
\hline C1-42-1.85-06 & 1067 & --- & Cut-off & 1 & 533 & 956 & 1.85 & $406 \times 508$ & $762 \times 508$ \\
\hline DC1-42-2.50-03 & 1067 & 533 & Cut-off & 1 & 533 & 956 & 2.50 & $406 \times 508$ & $457 \times 229$ \\
\hline SC1-42-1.85-03 & 1067 & 356 & Cut-off & 1 & 533 & 956 & 1.85 & $762 \times 508$ & $660 \times 229$ \\
\hline
\end{tabular}

Plate dimensions: [direction of span] $\times$ [perpendicular to span direction]

Table 8. Summary of specimen material strengths

\begin{tabular}{lccccccc}
\hline Specimen & $\begin{array}{c}f_{c}^{\prime} \\
(\mathrm{MPa})\end{array}$ & $\begin{array}{c}f_{y l} \\
(\mathrm{MPa})\end{array}$ & $\begin{array}{c}f_{y v} \\
(\mathrm{MPa})\end{array}$ & $\begin{array}{c}f_{y h} \\
(\mathrm{MPa})\end{array}$ & $\begin{array}{c}f_{y h a} \\
(\mathrm{MPa})\end{array}$ & $\rho_{v}$ & $\rho_{h}$ \\
\hline SS3-42-2.50-06 & 43.13 & 480 & 420 & 420 & 426.3 & $0.6 \%$ & $0.6 \%$ \\
C1-42-1.85-06 & 25.7 & 480 & 420 & 420 & 440 & $0.6 \%$ & $0.6 \%$ \\
DC1-42-2.50-03 & 27.8 & 480 & 430 & 430 & 440 & $0.3 \%$ & $0.3 \%$ \\
SC1-42-1.85-03 & 30 & 460 & 460 & 460 & 440 & $0.3 \%$ & $0.3 \%$ \\
\hline
\end{tabular}

Table 9. Distance from center of the load to the end of the ledge for three ledge types

\begin{tabular}{lcc}
\hline Ledge Type & $C_{1.85}$ & $C_{2.50}$ \\
\hline Cut-off & $(76.2 \mathrm{~mm})$ past bearing end & $(76.2 \mathrm{~mm})$ past bearing end \\
Short & $(901.7 \mathrm{~mm})$ & $(863.6 \mathrm{~mm})$ \\
Long & $(1768 \mathrm{~mm})$ & $(2390 \mathrm{~mm})$ \\
\hline
\end{tabular}




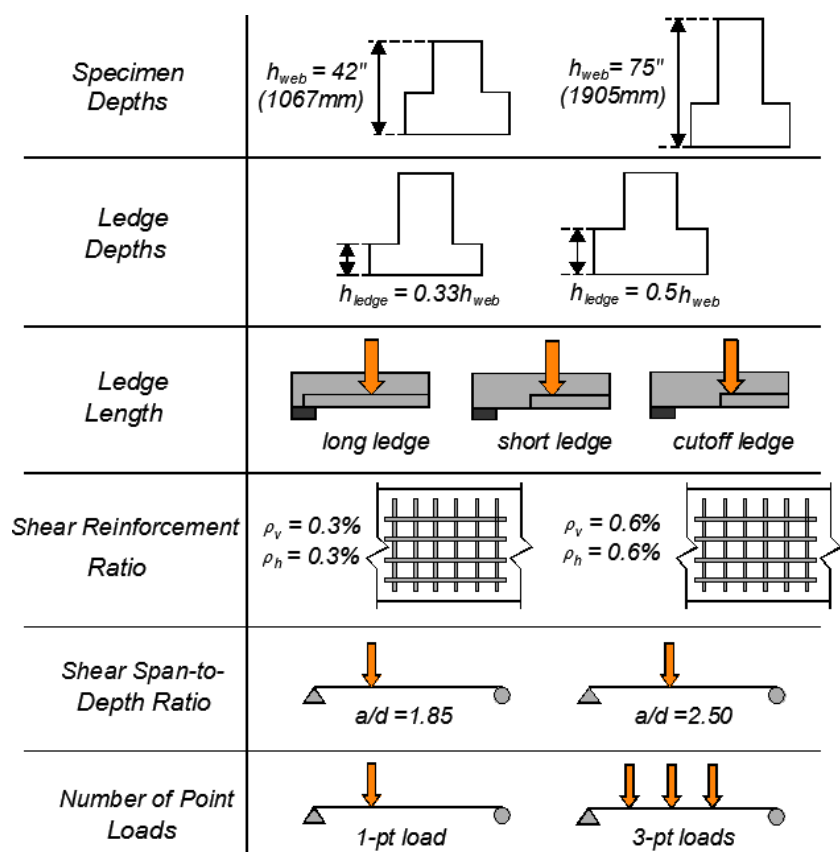

Fig. 16. Summary of experimental program

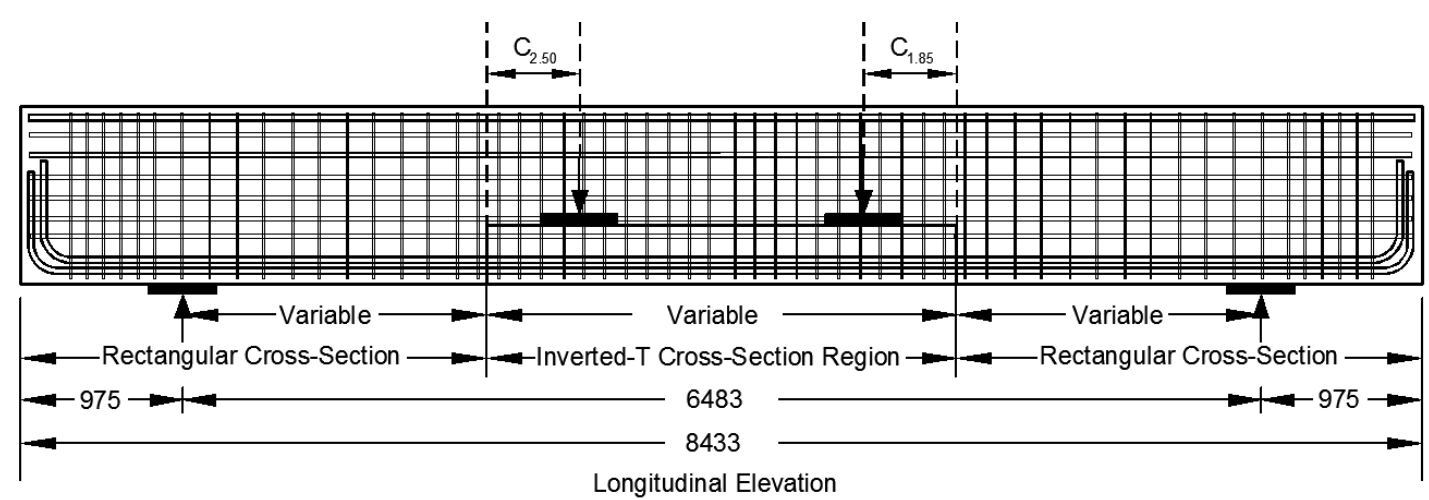

Fig. 17. Typical geometry for the 42 -inch $(1067 \mathrm{~mm})$ shallow specimens

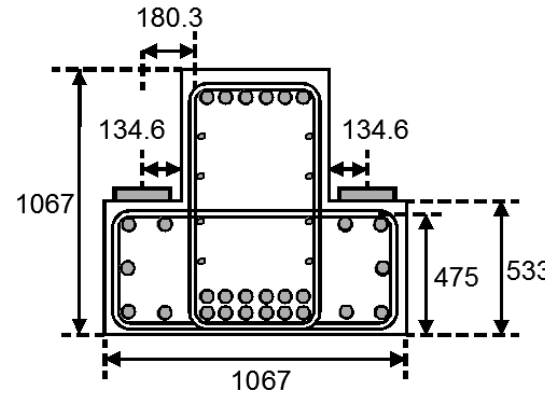

1067-mm. Deep ledge

Cross-Section

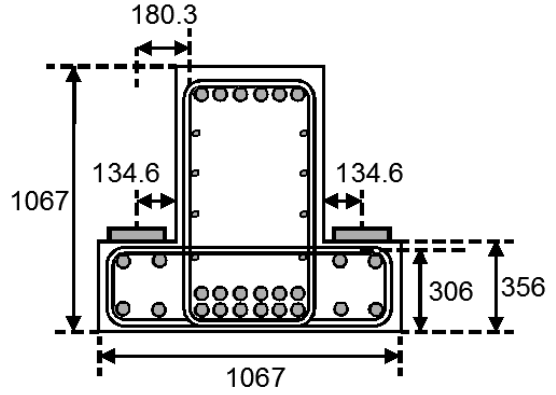

1067-mm. Shallow ledge Cross-Section

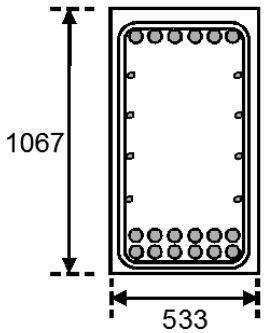

1067-mm. Rectangular Cross-Section (a) 42-inch (1067 $\mathrm{mm}$ ) deep ledge, half-depth ledge specimens (b) 42-inch (1067 mm) shallow ledge, (c) 42-inch (1067 mm) rectangular third-depth ledge specimens cross-Section

Fig. 18. Typical sections 
The value of the limiting compressive stress at the face of the node, $f_{c u}$, can be obtained from:

$f_{c u}=\mathrm{m} v f_{c}^{\prime}$

where $m$ is the triaxial confinement factor, $v$ is the concrete efficiency factor, and $f_{c}^{\prime}$ is the specified compressive strength of the concrete. The triaxial confinement factor, $m$, is calculated using the following equation: $\mathrm{m}=\sqrt{A_{2} / A_{1}}$, where $A_{1}$ is the loaded area and $A_{2}$ is measured on the plane defined by the location at which a line with a $2: 1$ slope extended from the loading area meets the edge of the member as shown in Fig. 19.

The concrete efficiency factors, $v$, are used to reduce the compressive strength of the concrete in the node depending on the type of node (CCC, $\mathrm{CCT}$, or CTT) and face (bearing face, back face, strut-to-node interface) under consideration. These factors are summarized in Table 10.

A three-dimensional strut-and-tie model as shown in Fig. 20 has to be considered, because the loads in Inverted-T beams are transferred from the ledges to the web, from the tension- to the compression-chord, and from the loading, points to support. However, for simplification, a threedimensional strut-and-tie model is decomposed into the two-dimensional longitudinal model and twodimensional cross-sectional model.

\section{Input data:}

The beam height, $h=1067 \mathrm{~mm}$, depth, $d=956 \mathrm{~mm}$, breadth, $b_{w}=533 \mathrm{~mm}$, ledge height, $h_{1}=356 \mathrm{~mm}$, ledge depth, $d_{1}=306 \mathrm{~mm}$, the load plate width $w_{l}=$ $229 \mathrm{~mm}$, and the load plate length $l_{l}=660 \mathrm{~mm}$, the support plate width $w_{s}=508 \mathrm{~mm}$, and the support plate length $l_{s}=762 \mathrm{~mm}$. The shear span, $L_{1}=1768$ $\mathrm{mm}$. The shear span-to-depth ratio, $a / d=$ $1768 / 956=1.85$. The tension steel, $A_{s}=12 \mathrm{~T} 36=$ $12077.4 \mathrm{~mm}^{2}$, and the compression steel, $A_{s}^{\prime}=$ $6 \mathrm{~T} 36=6038.7 \mathrm{~mm}^{2}$. The cylinder compressive strength of concrete, $f_{c}^{\prime}=30 \mathrm{MPa}=4330 \mathrm{psi}$. High strength deformed steel bars, with yield strength, $f_{\mathrm{y}-\mathrm{T} 36}=460 \mathrm{MPa}, f_{\mathrm{y}-\mathrm{T} 19}=440 \mathrm{MPa}$, and $f_{\mathrm{y}-\mathrm{T} 13}=460 \mathrm{MPa}$ and the vertical and horizontal web reinforcement are as shown in Fig. 21.
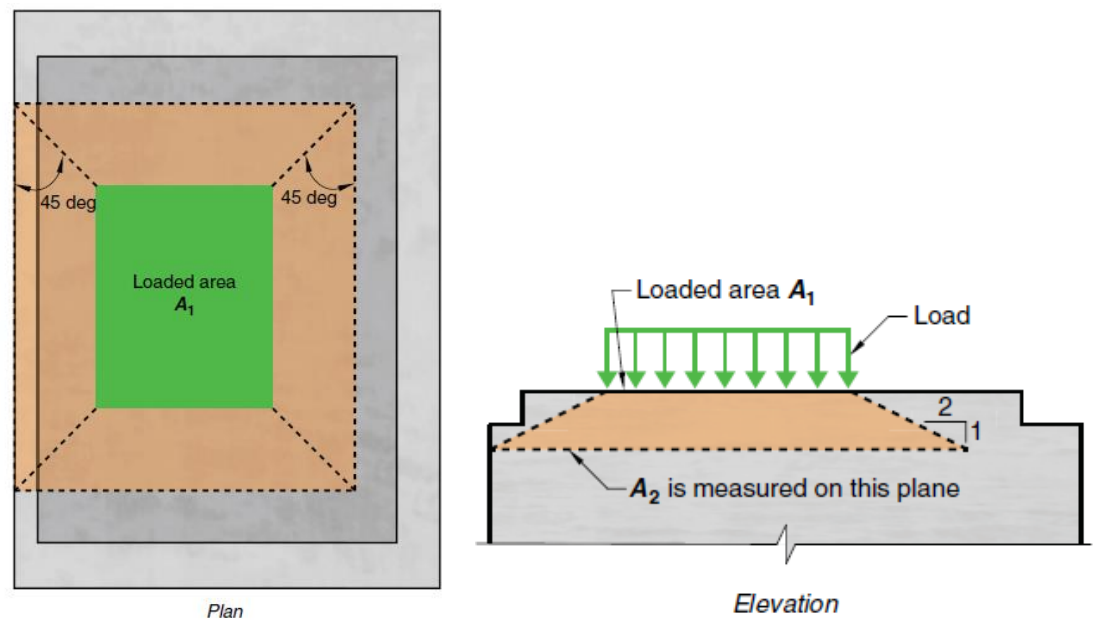

Fig. 19. Determination of $A_{2}$ for stepped or sloped supports [6]

Table 10. Concrete efficiency factors, $v$ [18]

\begin{tabular}{|c|c|c|c|}
\hline \multirow{2}{*}{ Face } & \multicolumn{3}{|c|}{ Node Type } \\
\hline & $\mathrm{CCC}$ & CCT & CTT \\
\hline Bearing & 085 & ( 70 & \\
\hline Back & 0.0 & 0.10 & $0.45 \leq 0.85-\frac{f_{c}^{\prime}}{20 \mathrm{ksi}} \geq 0.65$ \\
\hline Strut-to-node interface* & $0.45 \leq 0.85-\frac{f_{c}^{\prime}}{20 \mathrm{ksi}} \geq 0.65$ & $0.45 \leq 0.85-\frac{f_{c}^{\prime}}{20 \mathrm{ksi}} \geq 0.65$ & \\
\hline
\end{tabular}

* If crack control reinforcement requirement of AASHTO Art. 5.6.3.5 is not satisfied, use $v=0.45$ for the strut-to-node interface. 


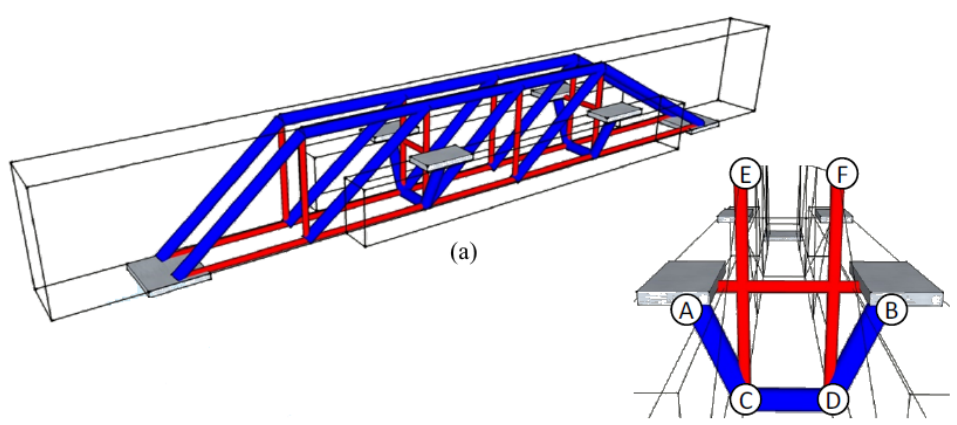

(b)

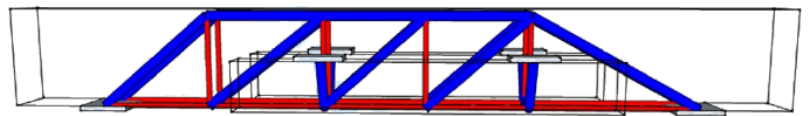

(c)

Fig. 20. STM of Inverted-T beam [23] (a) 3D STM; (b) 2D cross-sectional model; and (c) 2D longitudinal model

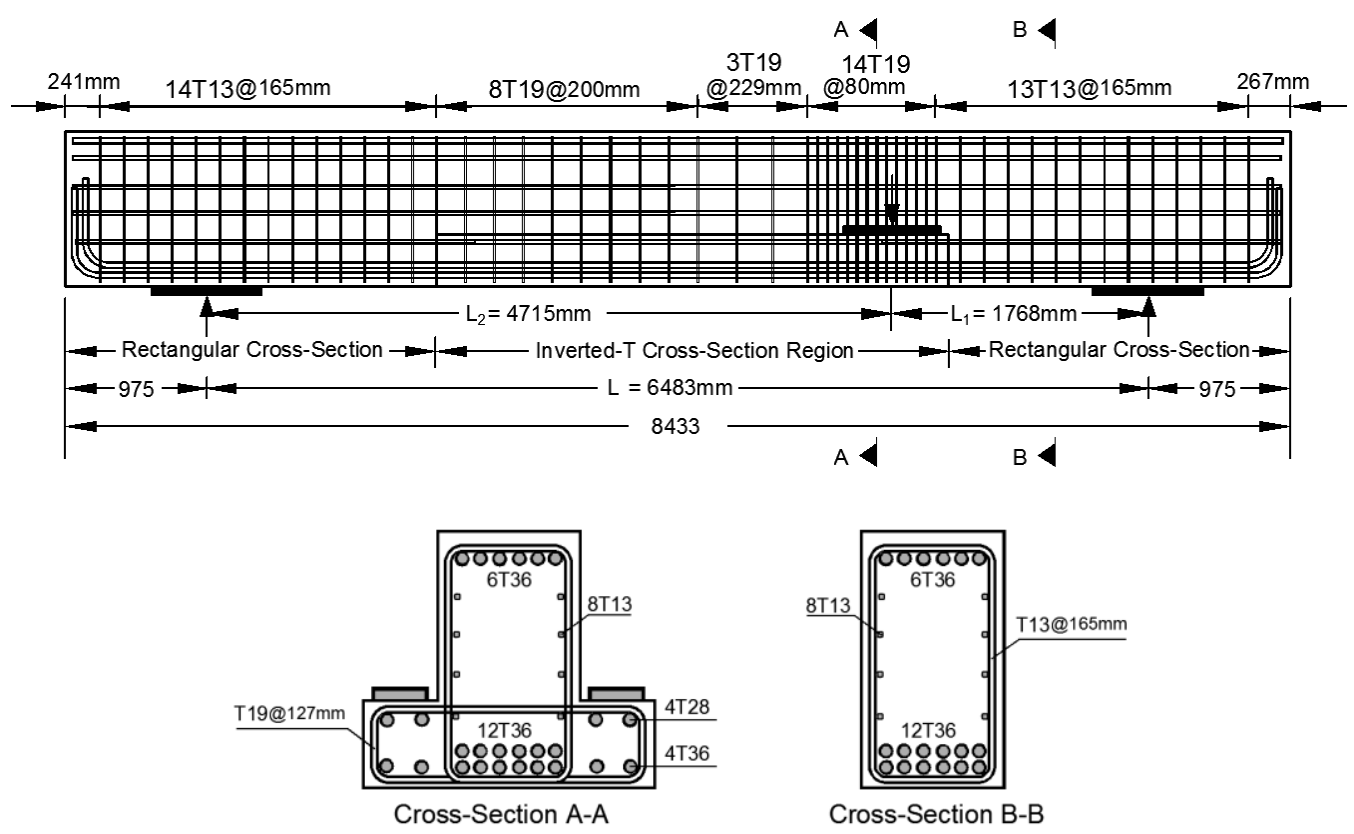

Fig. 21. Elevation and cross-sectional details of SC1-42-1.85-03

\subsubsection{Longitudinal STM model}

\subsubsection{Geometrical parameters}

The solution procedure starts with determining the geometrical layout for the longitudinal STM shown in Fig. 22. The $12 \mathrm{~T} 36$ reinforcement of each of the ties $T_{1}, T_{2}, T_{3}$, and $T_{4}$, give a nominal strength,
$T_{1 n}=T_{2 n}=T_{3 n}=T_{4 n}=A_{s} \times f_{\mathrm{y}}=5618.64 \mathrm{kN}$.

Since the reinforcement details allow the use of an extended nodal zone, the width of each of these ties (height of nodes A, C, E, G, and H) are $w_{T_{1}}=w_{T_{2}}=2(t-d)=2(1067-956)=222 \mathrm{~mm}$. 


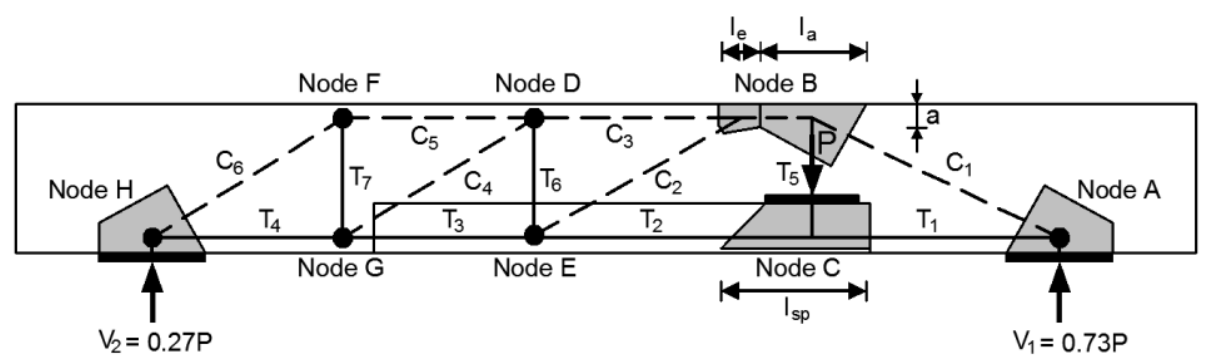

Fig. 22. Longitudinal strut-and-tie model for SC1-42-1.85-03

With reference to Fig. 22, the hanger ties, $T_{5}$ and $T_{6}$ are represented by (14T19) and (8T19), respectively, so their nominal strengths are

$T_{5 n}=A_{s} \times f_{\mathrm{y}}=(14 \times 2 \times 283.5) \times 440=3492.7 \mathrm{kN}$.

$T_{6 n}=A_{s} \times f_{\mathrm{y}}=(8 \times 2 \times 283.5) \times 440=1995.8 \mathrm{kN}$.

In the same manner, $T_{7}$ is represented by (7T13 +3T19), giving a nominal strength,

$T_{7 n}=A_{s} f_{\mathrm{y}}=[(7 \times 2 \times 132.7)(460)+(3 \times 2 \times$ 283.5)(440)] $=1603 \mathrm{kN}$.

\subsubsection{Reactions}

From linear elastic analysis, $V_{1}=0.73 P$ and $V_{2}=$ $0.27 P$

\subsubsection{Model geometry and forces}

In order to obtain the forces in the model elements, the reinforcement of a selected tie is assumed to reach its yield stress. The solution to this problem is initiated by assuming that the reinforcement of tie $T_{5}$ reaches its yield stress, $T_{5}=3492.7 \mathrm{kN}$. Then, from simple truss analysis, the model forces are obtained, Fig. 23. The size of the nodes has to be specified, to determine the locations of the struts and ties. The length of Node B in the longitudinal direction is determined by the spread length of the hanger tie $T_{5}, l_{s p}$. It is proportionally divided into $l_{e}$ and $l_{a}$ according to the amount of the applied load that acts on the left and right support [22].

The load spread

$$
\left(l_{s p}\right)=l_{l}+d_{1}+76.2 \mathrm{~mm}=1042.2 \mathrm{~mm}
$$

Portion of the load spread length, $l_{s p}$, on the right support $\left(l_{a}\right)=l_{s p} \times\left(L_{2} / L\right)=758 \mathrm{~mm}$
Portion of the load spread length, $l_{s p}$, on the left $\operatorname{support}\left(l_{e}\right)=l_{s p} \times\left(1-L_{2} / L\right)=284.2 \mathrm{~mm}$

Distance from center of length $l_{a}$ to the location of tie

$T_{5}\left(l_{a b}\right)=0.50 l_{a}+l_{e}-0.50 l_{s p}=142.1 \mathrm{~mm}$

Distance from center of length $l_{e}$ to the location of tie

$T_{5}\left(l_{b e}\right)=0.50 l_{e}+l_{a}-0.50 l_{s p}=379 \mathrm{~mm}$

Distance from the end of the load spread $l_{s p}$, to the left support

$\left.\left(l_{2.50}\right)=\left(L_{2}-l_{b e}\right) / 3\right)=1445.3 \mathrm{~mm}$.

The depth of the node is taken as the depth of the compression stress block, $a$,

$a=\frac{A_{s} f_{\mathrm{y}}-A_{s}^{\prime} f_{\mathrm{y}}}{0.85 b_{w} f_{c}^{\prime}}=206.7 \mathrm{~mm}$

Although a traditional flexural analysis is not valid in a D-region due to the nonlinear distribution of strains, defining $a$ using the equation above is conservative according to [22]. The moment arm, $y_{c t}=d-0.5 a=852.7 \mathrm{~mm}$.

7.2.1.4. The limiting compressive stress at the face of each node

The limiting compressive stress at the face of the node, $f_{c u}=\mathrm{m} v f_{c}^{\prime}$

A concrete efficiency factor, $v$, is applied to the concrete strength, $f_{c}^{\prime}$, to limit the compressive stress at the face of each node:

Bearing and back face of $\mathrm{C}-\mathrm{C}-\mathrm{C}$ node,

$v_{\mathrm{CCC}-\mathrm{b}}=0.85$

Bearing and back face of $\mathrm{C}-\mathrm{C}-\mathrm{T}$ node,

$v_{\mathrm{CCT}-\mathrm{b}}=0.70$ 


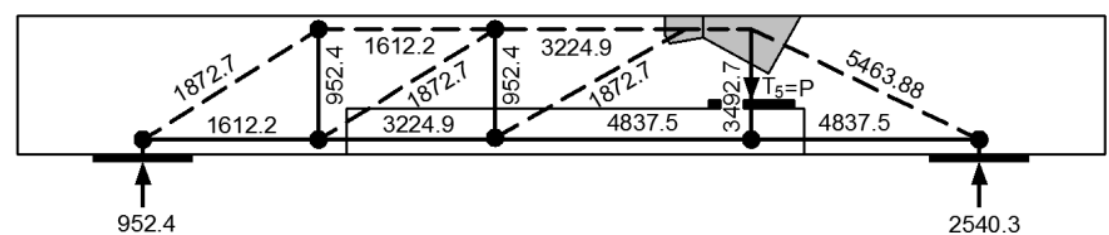

Fig. 23. Computed model forces $(k N)$ assuming yielding of $T_{5}$ reinforcement

CCC and CCT strut-to-node interface,

$v_{\text {CCT }- \text { stn }}=0.85-\frac{f_{c}^{\prime}}{20 \mathrm{ksi}}=0.85-\frac{4.33}{20}=0.634$

The triaxial confinement factor, $m$, is used to account for the effects of confinement provided by the concrete when the loaded area, $A 1$, is smaller than the supported area, $A 2$. In this case, the support plate is only $508 \mathrm{~mm}$ wide, whereas the beam is 533 mm wide.

$A l=l_{s} \times w_{S}=762 \times 508=387096 \mathrm{~mm}^{2}$

$A 2=\left(l_{s}+25 \mathrm{~mm}\right) \times\left(w_{s}+25 \mathrm{~mm}\right)=787 \times 533=419471$ $\mathrm{mm}^{2}$

$\mathrm{m}=\sqrt{A_{2} / A_{1}}=1.041$

Bearing and back face of $\mathrm{C}-\mathrm{C}-\mathrm{C}$ node, $f_{c u}^{C C C-b}=1.041 \times 0.85 \times 30=26.55 \mathrm{MPa}$.

Bearing and back face of $\mathrm{C}-\mathrm{C}-\mathrm{T}$ node, $f_{c u}^{C C T-b}=1.041 \times 0.70 \times 30=21.86 \mathrm{MPa}$.

CCC and CCT strut-to-node interface, $f_{\text {cu }}^{C C T-s t n}=1.041 \times 0.634 \times 30=19.80 \mathrm{MPa}$.

\subsubsection{Check the bearing of the nodes}

For node $\mathrm{A}$, the nominal value of the reaction $V_{1}$, $V_{1 n}=f_{c u}^{C C T-b} \times l_{s} \times w_{S}=21.86 \times 762 \times 508=8461.9 \mathrm{kN}$, which is greater than the reaction, $V_{1}=2540.3 \mathrm{kN}$. The nominal value of the load $P$,

$P_{n}=2 f_{c u}^{C C T-b} \times l_{l} \times w_{l}=2 \times 21.86 \times 229 \times 660=6607.8 \mathrm{kN}$ which is greater than the load, $P=3492.7 \mathrm{kN}$. For node $\mathrm{H}$, the nominal value of the reaction $V_{2}$, $V_{2 n}=f_{c u}^{C C T-b} \times l_{s} \times w_{s}=21.86 \times 762 \times 508=8461.9 \mathrm{kN}$ which is greater than the reaction, $V_{2}=952.4 \mathrm{kN}$.

\subsubsection{Check of stresses}

Only the critical nodes, the support nodes A and H, and the hanger node $\mathrm{B}$ are checked in the longitudinal model. The other nodes, such as the nodes D, E, F, and G in Fig. 22, are not critical and therefore they are not checked here.

Node A:

Since the bearing stress has been checked before, there is no need to check it again. The inclination angle of the strut $C_{1}, \theta_{1}=28.0^{\circ}$, which gives a width of the strut $w_{C_{1}}^{A}=762 \sin \theta_{1}+222 \cos \theta_{1}=$ $553.75 \mathrm{~mm}$. Then, the nominal strength of the strut $C_{1 n}=f_{c u}^{C C T-s t n} \times w_{C_{1}}^{A} \times w_{s}=19.8 \times 553.75 \times$ $508=5569.8 \mathrm{kN}$, which is greater than the strut force, $C_{1}=5463.88 \mathrm{kN}$.

\section{Node B:}

For strut $C_{2}$, its inclination angle $\theta_{2}=31.0^{\circ}$, which gives a width of the strut $w_{C_{2}}^{B}=\left[\left(l_{e}+a \tan \theta_{2}\right)\right.$ $\left.\sin \theta_{2}-\left(\frac{a}{\cos \theta_{2}}\right)\right]=-30.80 \mathrm{~mm}$. The contributions ratios of hanger tie width $l_{a}$ and $l_{e}$ have to be changed. Trials have been conducted until convergence takes place. Finally, the geometric parameters are obtained, $l_{a}=442.2 \mathrm{~mm}, l_{e}=600$ $\mathrm{mm}$.

The inclination angle of the strut $C_{1}, \theta_{1}=28.0^{\circ}$, which gives a width of the strut $w_{C_{1}}^{B}=442.2 \sin \theta_{1}$ $+206.7 \cos \theta_{1}=390.10 \mathrm{~mm}$. Then, the nominal strength of the strut $C_{1 n}=f_{c u}^{C C T-s t n} \times w_{C_{1}}^{B} \times b_{w}=$ $19.8 \times 390.10 \times 533=4116.9 \mathrm{kN}$, which is less than the strut force, $C_{1}=5463.88 \mathrm{kN}$; i.e., $\boldsymbol{C}_{\mathbf{1 n}}=\mathbf{0 . 7 5} \boldsymbol{C}_{\mathbf{1}}$.

For strut $C_{2}$, the inclination angle, $\theta_{2}=31.0^{\circ}$, which gives a width of the strut, $w_{C_{2}}^{B}=\left[\left(l_{e}+\right.\right.$ $\left.\left.a \tan \theta_{2}\right) \sin \theta_{2}-\left(\frac{a}{\cos \theta_{2}}\right)\right]=131.85 \mathrm{~mm}$. Then, the nominal strength of the strut, $C_{2 n}=f_{c u}^{C C T-s t n} \times w_{C_{2}}^{B}$ $\times b_{w}=19.8 \times 131.85 \times 533=1391.50 \mathrm{kN}$, which is 
less than the strut force, $C_{2}=1872.70 \mathrm{kN}$; i.e., $\boldsymbol{C}_{\mathbf{2 n}}$ $=0.74 C_{2}$.

For strut $C_{3}$, the nominal strength of the strut $C_{3 n}=f_{c u}^{C C T-s t n} \times a \times b_{w}+A_{s}^{\prime} f_{\mathrm{y}}=19.8 \times 206.7$ $\times 533+6107.25 \times 460=4990.72 \mathrm{kN}$, which is greater than the strut force, $C_{3}=3224.9 \mathrm{kN}$.

\section{Node H:}

Since the bearing stress has been checked before, there is no need to check it again. The inclination angle of the strut $C_{6}, \theta_{6}=31.0^{\circ}$, which gives a width of the strut, $w_{C_{6}}^{H}=762 \sin \theta_{6}+222 \cos \theta_{6}=$ $582.75 \mathrm{~mm}$. Then, the nominal strength of the strut $C_{1 n}=f_{c u}^{C C T-s t n} \times w_{C_{6}}^{H} \times w_{s}=19.8 \times 582.75 \times$ $508=5861.53 \mathrm{kN}$, which is greater than the strut force, $C_{6}=1872.70 \mathrm{kN}$.

From the obtained results the longitudinal STM model elements are all safe except elements $C_{1}$ and $C_{2}$, with $C_{2}$ is the most critical, $C_{2 n}=0.74 C_{2}$. Therefore, the load $P$ should be reduced to $74 \%$ of the calculated value; i.e., the predicted collapse load from the STM, $P_{S T M}=0.74 \times 3492.70=$ $2584.60 \mathrm{kN}$.

\subsubsection{Cross-Sectional STM model}

\subsubsection{Geometrical parameters}

The geometrical layout for the cross-sectional STM model is shown in Fig. 24a, where the numbering of ties, struts, and nodes are illustrated. Based on the last obtained load capacity from the longitudinal $S T M$ model, $P_{S T M}=2584.60 \mathrm{kN}$, the forces of the cross-sectional STM model can be obtained, Fig. $24 \mathrm{~b}$.

Truss geometry:

$l_{4}=45.7 \mathrm{~mm}_{1}=l_{4}+25.4 \mathrm{~mm}+0.50 w_{l}=185.6$ $\mathrm{mm}$

$l_{2}=b_{w}-2 l_{4}=441.6 \mathrm{~mm} \quad l_{3}=h_{1}+0.50 w_{T_{1}}+l_{s}=186.3 \mathrm{~mm}$ $l_{5}=58.7 \mathrm{~mm} \quad l_{n}=l_{s p}-w_{T_{1}}=820.2 \mathrm{~mm}$
With reference to Fig. 24, the reinforcement of tie $T_{A D}$ is represented by (12T19). The nominal strength of the tie is

$T_{A D n}=A_{s} \times f_{\mathrm{y}}=12 \times 283.5 \times 440=1497 \mathrm{kN}$,

which is greater than the tie force, $T_{A D}=$ $1292.3 \mathrm{kN}$.

\subsubsection{Check of stresses}

Since the cross-section and loading are symmetric, only one side needs to be checked.

\section{Node A:}

Since the bearing stress has been checked before, there is no need to check it again. For strut $C_{A B}$, the inclination angle, $\theta_{A B}=45.0^{\circ}$, which gives a width of the strut, $w_{C_{A B}}^{A}=w_{l} \sin \theta_{A B}+2 l_{5} \cos \theta_{A B}=$ $244.9 \mathrm{~mm}$. Then, the nominal strength of the strut, $C_{A B n}=f_{c u}^{C C T-s t n} \times w_{C_{A B}}^{A} \times l_{l}=19.8 \times 244.9 \times 660$ $=3200.9 \mathrm{kN}$, which is greater than the strut force, $C_{A B}=1827.6 \mathrm{kN}$.

\section{Node B:}

For strut $C_{A B}$, the inclination angle, $\theta_{A B}=45.0^{\circ}$, which gives a width of the strut, $w_{C_{A B}}^{B}=2 l_{4} \sin \theta_{A B}$ $+w_{T_{1}} \cos \theta_{A B}=221.6 \mathrm{~mm}$. Then, the nominal strength of the strut, $C_{A B n}=f_{c u}^{C C T-s t n} \times w_{C_{A B}}^{B} \times l_{s p}$ $=19.8 \times 221.6 \times 1042.2=4573 \mathrm{kN}$, which is greater than the strut force, $C_{A B}=1827.60 \mathrm{kN}$. The width of the prismatic strut, $C_{B C}$ is equal to $w_{C_{B C}}=w_{T_{1}}=$ $222 \mathrm{~mm}$. Then, the nominal strength of the strut, $C_{B C n}=f_{c u}^{C C T-s t n} \times w_{C_{B C}} \times l_{n}=19.8 \times 222 \times 820.2$ $=3605.3 \mathrm{kN}$, which is greater than the strut force, $C_{B C}=1292.3 \mathrm{kN}$.

Since the cross-sectional STM model elements are all safe, the $S T M$ capacity is governed by the longitudinal $S T M$ model, $P_{S T M}=0.74 \times 3492.70=$ $2584.60 \mathrm{kN}$. 


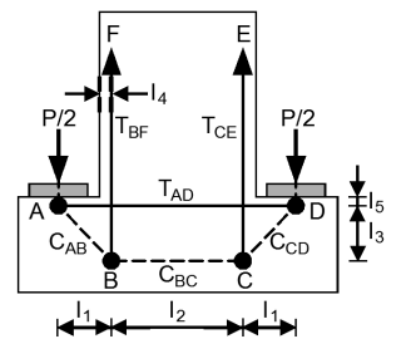

(a) cross-sectional model

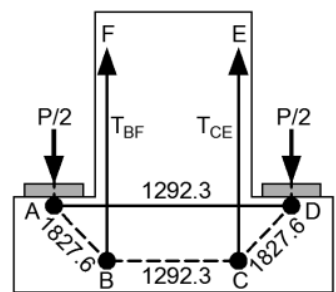

(b) model forces $(\mathrm{kN})$.

Fig. 24. Specimen SC1-42-1.85-03

The shear capacity calculated using STM provisions as implemented for Inverted-T beams, $V_{S T M}=0.73$ $\times P_{S T M}=0.73 \times 2584.6=1886.7 \mathrm{kN}$. The maximum shear carried in the critical section of the test region, including self-weight of the specimen and test setup is, $V_{\text {test }}=2060 \mathrm{kN}$. The critical section was considered to be the point halfway between the support and the nearest load. Then, the predicted collapse load from the STM is about $91.6 \%$ of the value measured in the test.

\subsection{Nonlinear finite element analysis of specimen SC1-42-1.85-03}

The specimen has been analyzed under the applied loads, with the right support is prevented from translation in the y-direction only, whereas the left support is prevented from translation in the $y$ - and $\mathrm{x}$-directions. Both linear and nonlinear analyses have been performed for the specimen as in the previous examples. The stress trajectories obtained from the linear elastic analysis are illustrated in Fig. $25 \mathrm{a}$ and the results obtained from the nonlinear analysis are presented in Figs. 25b to 25d.

As observed from the yielding stress zones in steel and the concrete plastic strain distribution, Figs. $25 \mathrm{~b}$ and $25 \mathrm{c}$, a local failure in the ledge due to tie yielding associated with web shear failure was the main cause of failure, which goes along with the experimental model of failure Fig. 25d. As observed from the experimental results, the horizontal ledge stirrups reinforcement yielded, whereas the stresses in vertical web stirrups were near yield, they reached $430 \mathrm{MPa}$. The maximum concrete compressive stress in the specimen near failure was $30 \mathrm{MPa}$. Neither the beam bottom nor the top longitudinal bars reached their yield stress; they reached $350 \mathrm{MPa}$ and $250 \mathrm{MPa}$, respectively. The predicted maximum shear carried in the critical section from the 3D nonlinear finite element analysis is $1920 \mathrm{kN}$, which is about $93.2 \%$ of the measured values.

\subsection{Predicted capacity and test}

The strength predicted by the STM and NFEA for the four specimens is given in Table 11, along with the measured values. The prediction from the STM, as expected, is on the safe side. On the other hand, as in the previous cases, the results from the NFEA are closer to the measured strength.

\section{Conclusions}

The focus of this study was to investigate the applicability and reliability of the strut-and-tie modeling and the 3D nonlinear finite element analysis for the prediction of the capacity and behavior of discontinuity regions. The study aimed to demonstrate the complementary role of the two methods as design tools. The two methods have been successfully applied to different problems, simply supported deep beam with large opening and recess, continuous deep beams with and without large openings, and inverted beams with ledges. The solutions obtained by the two methods for the selected problems have been verified by experimental tests.

From the obtained results the following conclusions can be drawn:

1. Both the nonlinear finite element and strut-andtie method are reliable as design tools for the prediction of the strength and behavior of 
reinforced concrete structures with discontinuity regions.

2. The strut-and-tie method as a lower-bound solution always yields a safe solution. Also, the STM serves as a design tool where the designer can trace the flow of forces and hence can easily develop efficient reinforcement details.

3. The nonlinear finite element analysis provides a more accurate prediction of the ultimate strength than the strut-and-tie method; however, there is no guarantee that it provides a safe solution in every case. Besides, the computation effort of the NFEA is tedious in co comparison with the STM. Clear that the NFEA provides a useful tool in understanding the behavior of reinforced concrete structures with discontinuity regions concerning stiffness and deformations.
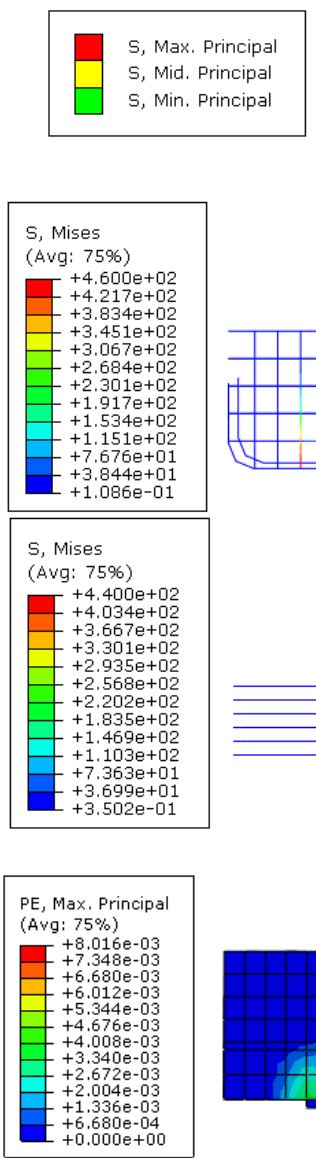

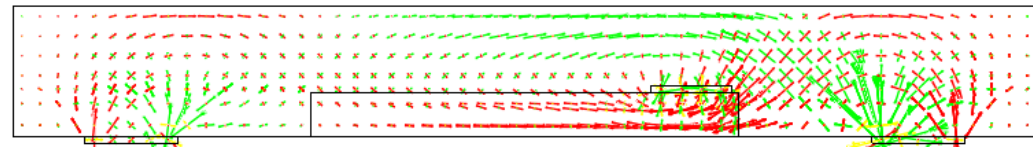

(a) stress trajectories
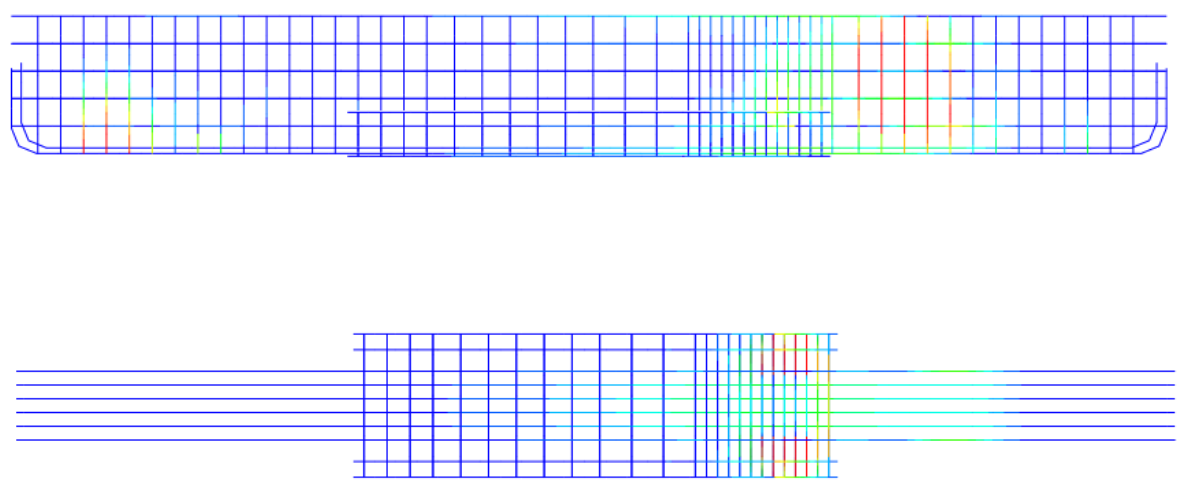

(b) yielding stress zones (elevation and plan)

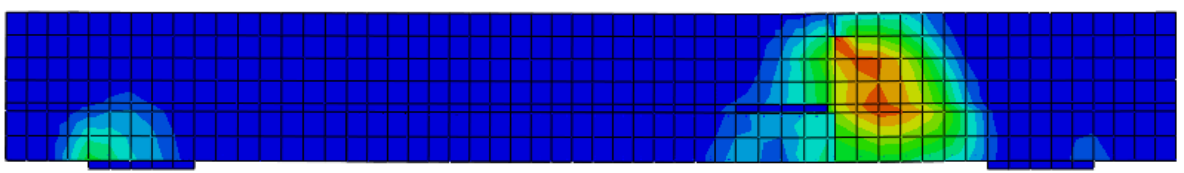

(c) concrete plastic strain distribution

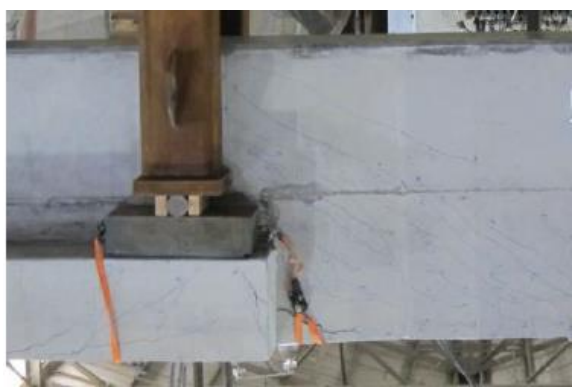

(d) experimental cracking patterns at the ultimate test load

Fig. 25. Finite element results of specimen SC1-42-1.85-03 
Table 11. Strength of ledge beam specimens

\begin{tabular}{lcccccc}
\hline Specimen & $f_{c}^{\prime}(\mathrm{MPa})$ & $V_{\text {STM }}(\mathrm{kN})$ & $V_{\text {NFEA }}(\mathrm{kN})$ & $V_{\text {Test }}(\mathrm{kN})$ & $V_{\text {STM }} / V_{\text {Test }}$ & $V_{F E} / V_{\text {Test }}$ \\
\hline SS3-42-2.50-06 & 43.13 & 1846 & 2150 & 2295.3 & 0.80 & 0.93 \\
C1-42-1.85-06 & 25.7 & 1904 & 2570 & 2833.5 & 0.67 & 0.91 \\
DC1-42-2.50-03 & 27.8 & 1152 & 1500 & 1623.6 & 0.71 & 0.92 \\
SC1-42-1.85-03 & 30 & 1886.7 & 1920 & 2060 & 0.92 & 0.93 \\
\hline
\end{tabular}

\section{Declaration of conflicting interests}

The author(s) declared no potential conflicts of interest concerning the research, authorship, and/or publication of this article.

\section{References}

[1] El-Metwally SE, Chen WF (2017) Structural Concrete: Strut-and-Tie Models for Unified Design. CRC Press, New York.

[2] Schlaich J, Schäfer K, Jennewein M (1987) Toward a consistent design of structural concrete. Journal of the Prestressed Concrete Institute 32(3): 74-150.

[3] Ritter W (1899) Die bauweise Hennebique. Schweizerishe Bauzeitung (Zürich) 33(7): 59-61.

[4] Mörsch E (1899) Der Eisenbetonbau, seine Theorie und Anwendung. Herausgegeber der ersten und zweiten Auflage. Stuttgart: K. Wittwer. 3rd edition translated into English by E. P. Goodrich, McGrawHill Book Co., New York, 1909.

[5] Schlaich J, Schäfer K (1991) Design and detailing of structural concrete using strut-and-tie models. Journal of the Structural Engineer 69(6): 113-125.

[6] ACI Committee 318. Building code requirements for structural concrete (ACI 318-14) and commentary. American Concrete Institute, Farmington Hills, MI, 2014.

[7] Eurocode 2. Design of concrete structures. October, 2001.

[8] Canadian Standards Association. Design of concrete structures (CSAA23.3-94). Ontario: Rexdale, 1994.

[9] Comite' Euro-International du Be'ton. CEB-FIP model code 1990. London, UK: Thomas Telford Services, Ltd., p. 437, 1993.

[10] FIP Commission 3. Practical design of structural concrete. Lausanne, Switzerland: Fe'de'ration internationale de la Pre'contrainte, p. 114, 1999.

[11] ABAQUS (2019) Abaqus/CAE User's Manual, Dassault Systèmes Simulia Corp., Providence, RI, USA.
[12] Saenz LP (1964) Discussion of "Equation for the stress-strain curve of concrete" by Desayi and Krishman. ACI J 61(9): 1229-1235.

[13] Hu H, Schnobrich W (1989) Constitutive modeling of concrete by using nonassociated plasticity. Journal of Materials in Civil Engineering (ASCE) 1(4): 199-216.

[14] ACI-318. Building code requirements for structural concrete and commentary. Detroit (MI), USA: American Concrete Institute, 1999.

[15] Novak L, Sprenger H. Example 4: Deep beam with opening, In: Examples for the design of structural concrete with strut-and-tie models. SP 208. ed. Reineck, K.-H. American Concrete Institute, 2002.

[16] Ashour AF (1997) Tests of reinforced concrete continuous deep beams. ACI Structural Journal 94(1): 3-12.

[17] Wu T, Li B (2009) Experimental verification of continuous deep beams with openings designed using strut-and-tie modeling. The IES Journal Part A: Civil and Structural Engineering 2(4), 282-295.

[18] Larson N, Gómez EF, Garber D, Bayrak O, Ghannoum W (2013) Strength and serviceability design of reinforced concrete inverted-T beams. The University of Texas at Austin Technical Report 0-6416-1.

[19] Garber DB, Varney NL, Gómez EF, Bayrak O (2017) Performance of ledges in inverted-T beams. ACI Structural Journal 114(2): 487-498.

[20] AASHTO LRFD. Bridge design specifications. American Association of State Highway and Transportation Officials, Washington, D.C., 2012.

[21] Birrcher D, Tuchscherer R, Huizinga M, Bayrak O, Wood S, Jirsa J. Strength and serviceability design of reinforced concrete deep beams. Center for Transportation Research, the University of Texas at Austin, Report No: 0-5253-1, 2009.

[22] Williams C, Deschenes D, Bayrak O (2012) Strutand-tie model design examples for bridges: Final report. The University of Texas at Austin, Report No: 5-5253-01-1. 
[23] Fernández-Gómez E, Larson N, Garber D, Ghannoum W, Bayrak O (2011) Strength and serviceability of reinforced concrete inverted-T straddle bent caps. PCI/NBC Conference Proceedings. 